UNIVERSITY OF WISCONSIN-LA CROSSE

Graduate Studies

CAN THE TALK TEST BE USED TO CONTROL EXERCISE INTENSITY?

A Manuscript Style Thesis Submitted in Partial Fulfillment of the Requirements for the Degree of Master of Science in Clinical Exercise Physiology

Michaela L. Woltmann

College of Science and Health

Department of Exercise and Sport Science

Clinical Exercise Physiology

May, 2013 


\section{CAN THE TALK TEST BE USED TO CONTROL EXERCISE INTENSITY?}

By Michaela L. Woltmann

We recommend acceptance of this thesis in partial fulfillment of the candidate's requirements for the degree of Master of Science in Clinical Exercise Physiology.

The candidate has completed the oral defense of the thesis.

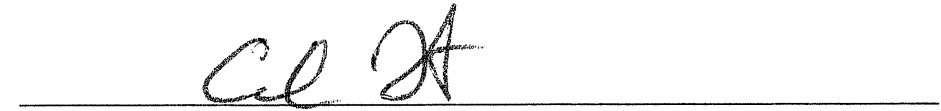

Carl Foster, Ph.D.

Thesis Committee Chariperson

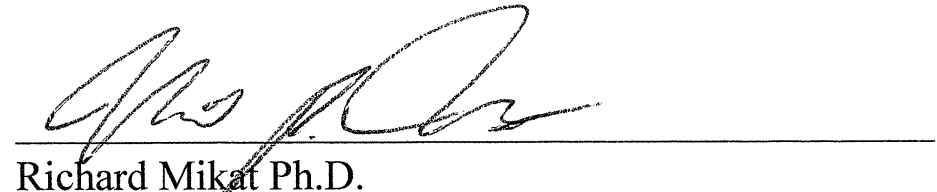

Thesis Committee Member

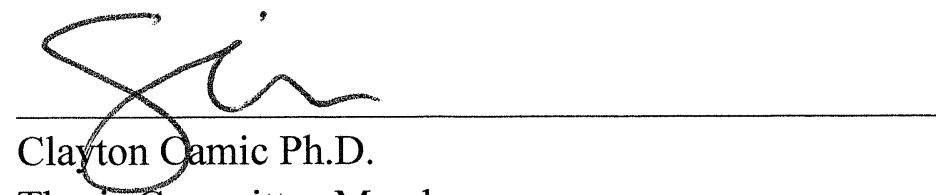

Thesis Committee Member

Thesis accepted

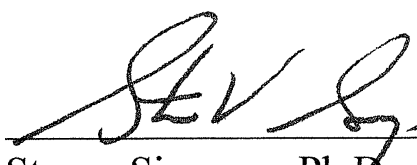

Steven Simpson, Ph.D.

Graduate Studies Director
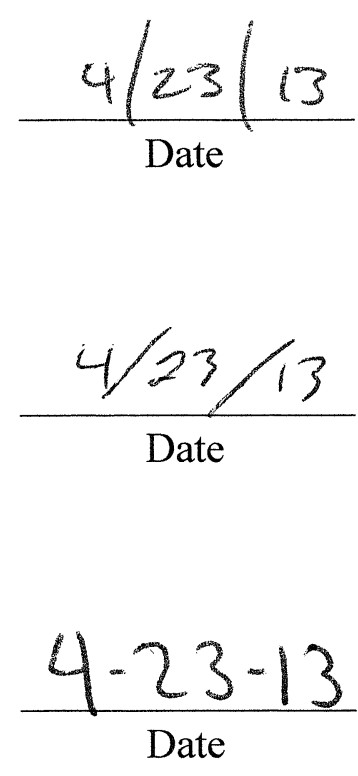


\begin{abstract}
Woltmann, M.L. Can the talk test be used to control exercise intensity? MS in Clinical Exercise Physiology, May 2013, 62pp. (C. Foster)

Introduction: The Talk Test has been shown to be an effective surrogate of standard methods of prescribing exercise training intensity, and is responsive to manipulations known to change physiologic function. It is not known if the Talk Test can be used as a control tool for regulating training intensity. Methods: Physically active volunteers $(n=16)$ performed an incremental exercise test to identify stages of the Talk Test (LP-1, LP, EQ, NEG). In subsequent, randomly ordered, 30 min steady state runs, the running velocity was regulated by 'clamping' the TT stage desired, and conventional markers of exercise intensity (Heart Rate, Blood Lactate, Rating of Perceived Exertion) were monitored. Results: All subjects could complete the LP-1 and LP states, with 13 and 2 subjects able to complete the EQ and NEG stages, respectively. Physiologic responses were broadly within those predicted from the incremental exercise test, and within the range of physiologic responses appropriate for exercise training. The LP-1 and LP stages generally produced intensities compatible with training intensity in healthy adults, the EQ and NEG stages produced intensities compatible with training in athletes. Conclusion: The Talk Test can be used simply to control exercise training intensity.
\end{abstract}




\section{ACKNOWLEDGEMENT}

I would first like to thank Dr. Carl Foster for his guidance throughout this process. His expertise and support were essential to my success. Working with Carl has been a wonderful experience, one that I will continue to learn from long after I leave here. I would like to also thank Dr. Richard Mikat and Dr. Clayton Camic for agreeing to be on my thesis committee and helping me with my research along the way. In addition, I would like to thank John Porcari, Kristi Cadwell, Christopher Dodge, and the LEHP participants who all played a vital role in completing this academic process. I would like to thank my family, specifically my parents for without their endless support and encouragement, I would not be where I am today. I would also like to thank my friends and classmates for their support and all of the laughs along the way. And finally, I would like to thank Mike Van Hierden. His love and support has been everything to me this past year. I couldn’t have succeeded without you all. Thank you! 


\section{TABLE OF CONTENTS}

PAGE

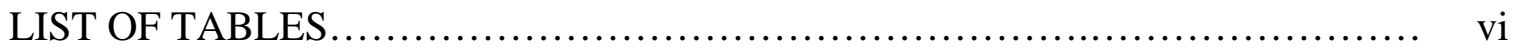

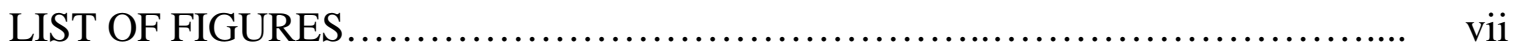

LIST OF APPENDICES....................................................... ix

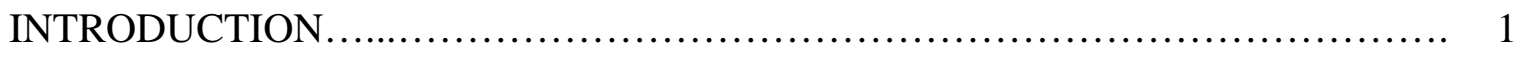

METHODS................................................................. 11

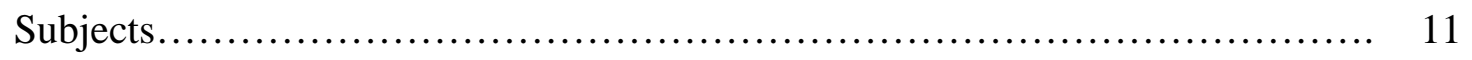

Table 1. Descriptive Characteristics of Subjects.............................. 11

Procedures............................................................. 11

Statistical Analysis...................................................... 14

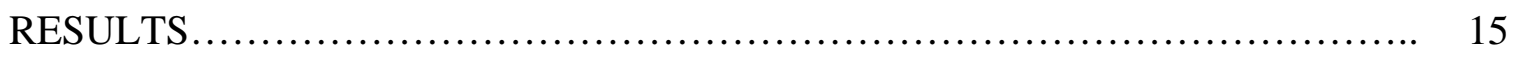

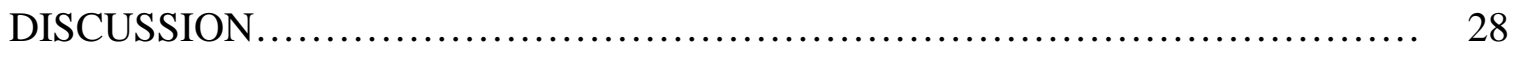

Conclusion............................................................ 29

REFERENCES............................................................. 30

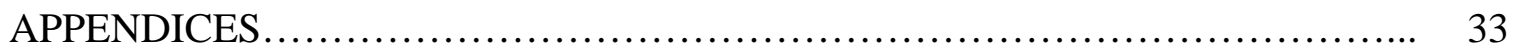




\section{LIST OF FIGURES}

FIGURE

PAGE

1. Talk test responses across the 30-minute time trials (LP-1, LP, EQ, NEG).

2. Physiological marker comparisons between maximal gas exchange (GE) and

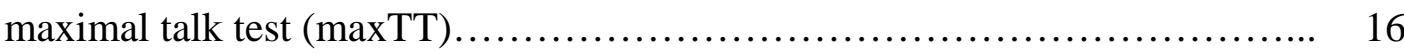

3. Changes in speed across the 30 -minute time trials (LP-1 and LP) ............ 17

4. Percentage of initial speed maintained during each 2-minute segment of the

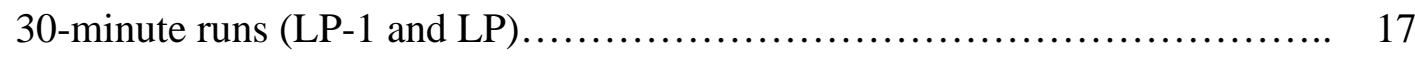

5. Percentage of heart rate reserve during the 30-minute time trials (LP-1 and LP) 18

6. Percentage of heart rate fluctuations during the 30 -minute time trials (LP-1 and

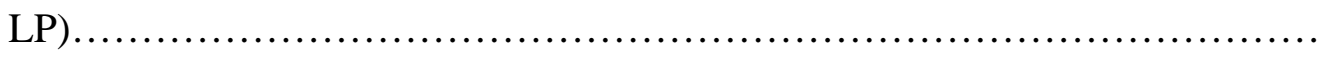

7. RPE fluctuations during the 30 -minute time trials (LP-1 and LP)............ 19

8. [HLa] fluctuations during the 30-minute time trials (LP-1 and LP) ........... 20

9. Number of subjects who completed each 30 -minute time trial............... 22

10. Average time (in minutes) in completion of each 30 -minute time............. 23

11. Speed fluctuations during each 30-minute time trial (EQ and NEG)........... 23

12. Percentage of initial speed maintained every 2-minute segment during each 30-minute time trial (EQ and NEG) ................................. 24

13. Heart rate fluctuations during each 30-minute time trial (EQ and NEG)........ 25

14. Percentage of heart rate reserve during each 30-minute time trial (EQ and

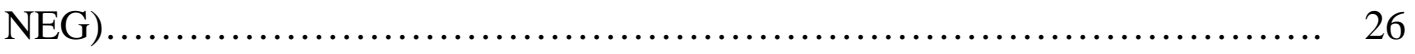

15 RPE fluctuations during each 30-minute time trial (EQ and NEG)........... 26 
16. [HLa] fluctuations during each 30-minute time trial (EQ and NEG)............ 


\section{LIST OF APPENDICES}

APPENDIX

PAGE

A. $\quad$ Physical Activity Readiness Questionnaire (PAR-Q) ....................... 36

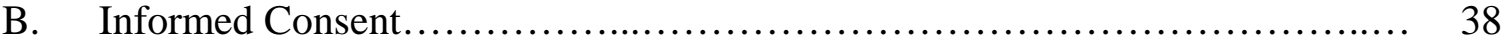

C. $\quad$ Review of Literature....................................................... 42 


\section{INTRODUCTION}

While it is established that regular exercise provides a variety of health benefits, it is unclear what is appropriate for individual exercise prescription. Based on a substantial body of evidence from experimental training studies, exercise prescription has traditionally been based on relative percentages of maximal exercise test results such as heart rate (HRmax), heart rate reserve (HRR), oxygen uptake $\left(\mathrm{VO}_{2} \mathrm{max}\right)$, percent oxygen uptake $\left(\% \mathrm{VO}_{2} \mathrm{max}\right)$, peak power output (PPO), ventilatory threshold (VT), lactate threshold (LT), respiratory compensation threshold (RCT), and maximal lactate steady state (MLSS) (ACSM, 2010; Mezzani et al. 2012). However, lack of both resources and the availability of trained professionals to conduct maximal exercise tests has dictated that ideal methods of exercise prescription are impractical.

The American College of Sports Medicine (ACSM, 2010) has published exercise guidelines for both general and clinical populations. Exercise prescription is based on the F.I.T.T. Principle, representing frequency, intensity, time, and type of exercise. While frequency, time, and type of exercise are relatively simple to comprehend, exercise intensity is the most difficult aspect of an exercise training program to correctly prescribe. This has been a problem for the general population, for athletes, and in medically prescribed exercise programs. The reason for this is simply that every individual's physiology is different and therefore, objective measures of exercise intensity do not always produce the same subjective results. As long as 35 years ago, 
Katch, Weltman, Sady, \& Freedson (1978) pointed out the limitations of the "relative percent concept”. This suggestion has been reinforced more recently (ScharhagRosenberger, F. Meyer, T. Gassler, N. Faude, O. \& Kindermann, W. 2009). This, together with the lack of availability of maximal exercise testing results (which are central requirements of the relative percent concept) has led to the popularization of subjective methods of measuring exercise intensity such as the Rating of Perceived Exertion Scale (RPE) (Borg, 1998) and the Talk Test (TT). While the RPE scale has been widely accepted in the field of exercise physiology, particularly into the majority of cardiac rehab programs, (cf. Eston, 2012) the TT has remained somewhat less well accepted.

The concept behind the TT was originally articulated in 1939 by Professor Henry Joseph Grayson through advice he gave to British mountaineers to "climb no faster than you can talk.” This simple recommendation is the groundwork for what may be a superior subjective method of measuring exercise intensity, the Talk Test. The TT has been further studied and developed since it was included in the ACSM Guidelines for Exercise and Training volume 4 in 1991. However, it has since been taken out of the guidelines due to lack of support from other major organizations. More recently, a substantial body of evidence supporting the validity of the TT has emerged, both from our laboratory (Brawner et al. 2006; Cannon et al. 2004; Dehart-Beverly, Foster, Porcari, Fater, \& Mikat, 2000; Foster et al. 2008; Foster et al. 2012; Persinger, R., Foster, C., Gibson, M., Fater, D. C. W., \& Porcari, J. P., 2004; Rodriguez-Marroya, J.A., Villa, G., Garcia-Lopez, J.G., \& Foster, C. 2012; Voelker et al. 2001) and elsewhere (Loose et al. 
2012; Norman, Kracl, Parker, \& Richter, 2002; Norman, Hopkins, \& Crapo, 2008;

Zanettini et al. 2012.)

The protocol for the TT is quite simple. The individual performs incremental exercise, with stages of two to three minutes duration. Near the end of each stage, the individual uses a standard speech provoking stimulus, and is asked "can you speak comfortably?” There are three results that can be achieved; a positive TT, which in this study was indicated as either the Last Positive stage (LP) or the stage prior to the Last Positive stage (LP-1), an equivocal test (EQ), and a negative (NEG) test. In order to attain a positive TT, the subject must be able to speak comfortably while exercising. If the subject is at all unsure whether they are able to speak comfortably, this results in an EQ TT. If the subject is definitely unable to speak comfortably during an exercise test, this results in a NEG TT. Different protocols have been used in studies conducting the TT but the two most common are: 1) having the subject read a standard paragraph during the last thirty seconds of each exercise stage, commonly the Pledge of Allegiance (POA) or 2) having the subject listen to a previously recorded interview and respond to the questions out loud. The subjects are then asked if they are able to speak comfortably, and they can answer in one of three ways; 1) “yes”, indicating a positive test, 2) “I'm not sure”, or anything but a "yes”, indicating an EQ test, and 3)" No”, indicating a NEG test.

The logic behind the TT is related to the principles of speech production. Meckel, Y., Rotstien, A., \& Inbar, O. (2002) examined the cardiopulmonary and metabolic responses to speech during exercise of varying intensities in healthy young men. They found that to allow adequate speech production, one must adapt their breathing pattern to one that allows them to take in the required amount of oxygen. The results of this study 
concluded that speech production is correlated with an increase in oxygen cost, a decrease in oxygen consumption, and therefore a decrease in ventilatory efficiency. During speech production, inspiration time decreases while expiration time increases resulting in a significant decrease in overall ventilation. More specifically, the decrease in $\mathrm{VO}_{2}$ during speech while exercising was accompanied by a significant drop in ventilation as well as an increase in blood lactate concentration ([HLa]). However, only the lowest intensity exercise bout produced such changes in [HLa] and it remains unclear as to why the increases in the other two (more difficult) exercise bouts were smaller and not significant.

With this information considered, an observation that breathing frequency increases markedly at the intensity of the VT, it is common sense that during exercise at higher intensities, speech production becomes more difficult. This concept is what has led researchers to believe that the TT is highly related to the VT. Dehart-Beverly et al. (2000) produced results indicating that the TT is a surrogate of VT. Results from this study suggested that during the positive stages of the TT, subjects were exercising below their VT (and within recommended guidelines from the ACSM). During the NEG stage of the TT, subjects were exercising beyond their VT (therefore exceeding the ACSM recommendations for exercise). The EQ stage occurred at exercise intensities essentially equal to the VT. These findings were reproduced in several other studies with different subject populations conducted by, Voelker et al. (2000), Recalde et al. (2000), Persinger et al. (2004), and Foster et al. (2008, 2012).

In addition to the TT being highly related to the VT, research has shown it to be highly related to the LT as well. Quinn \& Coons (2011) conducted a study that aimed to 
identify differences between measured physiological and perceptual variables at the LT and VT. In addition they examined what effects the TT had on such variables at each threshold and if they were comparable. The results demonstrated that during the positive stage of the TT, subjects were below their LT. During the EQ and NEG stages of the TT, subjects were above their LT. Additional findings of this study were that: 1) the physiological and perceptual values during the LP stage of the TT were significantly lower than physiological and perceptual values recorded at the LT and, 2) the physiological and perceptual values during the EQ and NEG TT stages were significantly higher than physiological and perceptual values at the LT. These findings suggest that in response to the TT, VT and LT produce comparable effects during the positive, EQ, and NEG stages, supporting the concept that the TT is a valid surrogate method of both physiological markers.

The validity of the TT has since been tested in a variety of populations. To evaluate the consistency of the TT and its ability to be used among different populations, the validity and reproducibility the TT have been tested in clinical, sedentary, and athletic/physically active populations. Cannon et al. (2004) demonstrated that amongst patients with evidence of exertional ischemia, that so long as the patients were at the positive stage of the TT, that they were below their ischemic threshold. The results of this study showed that the exercise time, heart rate (HR), and RPP were significantly lower during the LP stage of the TT than at the first onset of electrocardiographic evidence of ischemia. In $84 \%$ of the subjects, the LP stage of the TT preceded the ischemic threshold and produced HR's approximately 10 beats below the onset of ischemic symptoms (which is consistent with ACSM's recommendations for target HR's 
in patients with exertional ischemia). However, the small number of subjects in this study warrants further research to be done on this topic.

Voelker et al. (2002) observed the relationship between the TT and the VT in cardiac patients. By the time of this study, research had already indicated that the TT was a valid subjective method of measuring exercise intensity compared to traditional objective methods in apparently healthy individuals (Dehart-Beverly et al. 2000), but the validity of the TT in cardiac patients remained questionable. The results of Voelker et al. (2002) were consistent with the results of the Dehart-Beverly et al. (2000) study in respect to the LP and EQ stages producing exercise intensities below the subjects' VT and the NEG stage producing exercise intensities above the subjects' VT. These results suggested that the TT could be applied to exercise prescription for people with stable cardiovascular disease.

Extending research indicating the TT was a valid measurement of exercise intensity in both healthy and cardiac patients, Recalde et al. (2002) applied this concept to well-trained individuals. His results were similar to the results from Dehart-Beverly et al. (2000) and Voelker et al. (2002). The positive stages of the TT were consistently below the VT and the negative stages of the TT was almost exactly at the RCT, indicating the TT to be appropriate for guiding exercise training in physically active populations as well.

In 2009, Foster and colleagues conducted a separate study evaluating the possibility of translating submaximal exercise test responses to exercise prescription in sedentary adults. More specifically, this study examined what happens to exercise intensity when TT responses observed during incremental exercise were applied to steady 
state exercise training. This study required subjects to perform an incremental treadmill test where HR, RPE, and TT responses were recorded. This was done to measure at what intensities each subject was working at during each stage of the TT. Subjects then performed three 20-minute exercise bouts with the workload (during the last 10 minutes of each bout) adjusted to be at the absolute intensity of: 1) LP-1, 2) the LP Stage, and 3) the EQ Stage. In all three stages, the steady state exercise produced results of \%HRmax and MET levels within ACSM's guidelines. However, the subjective responses of the subjects exceeded the ACSM guidelines. More specifically, without decreasing the absolute intensity by one level before the incremental exercise stage where comfortable speech was last observed, subjects could not sustain adequate speech during steady state exercise. This study further reinforces the inaccuracy of prescribing exercise based on solely objective results (Foster et al. 2009).

The concept that exercise intensity needed to be reduced to that of the stage before the LP stage lead to the research conducted by Jeans, E.A., Foster, C., Porcari, J. P., Gibson, M., \& Doberstein, S. (2011) that evaluated how much of a reduction in absolute exercise intensity was needed to produce adequate speech in well-trained individuals. Similar to Foster's work in 2009, her results showed that for well-trained or athletic populations, absolute exercise intensity should be reduced to that of the LP-1 and LP stages. This data suggested that the TT was not only strong in its validity, but its reproducibility as well.

In 2012, Foster and colleagues conducted another study evaluating the ability of TT responses during an exercise test to guide exercise training in competitive runners. Steady state conditions were observed at the absolute intensity associated with the LP 
stage of the TT. However, absolute intensities at the EQ stage of the TT produced results (HR, [HLa], RPE, and speech comfort) that exceeded steady state conditions. These results are in agreement with the study by Jeans et al. (2011) but differ from the results of Foster et al. (2009) in that steady state conditions were observed at the LP stage instead of the LP-1 stage (Foster et al. 2012).

The only study conducted thus far evaluating the ability of subjective measurements of exercise 'clamped' to control exercise intensity was a study by Parfitt, Evans, \& Eston, (2012). This study measured the ability of a Perceptually Regulated Training (PRET) clamped at an RPE of 13 to improve aerobic fitness and cardiovascular health. Due to the variability of subjective responses to exercise intensity previously examined in other studies (Katch et al. 1978; Scharhag-Rosenberger et al. 2009), clarification of how to accurately prescribe exercise remains problematic. In this randomized study, sedentary volunteers were assigned to a training group or a control group. All subjects completed a maximal incremental exercise test to measure their aerobic capacity. The training group then followed a PRET program clamped at an RPE of 13 three times a week for eight weeks while the control group participated in no training at all. The data revealed that in the training group, both fitness and cardiovascular health improved. Specifically, a PRET program clamped at an RPE of 13 produced improvements in $\mathrm{VO}_{2}$ max, mean arterial pressure (MAP), total cholesterol, and body mass index (BMI). Additionally, the training program clamped at an RPE of 13 produced intensities that the subjects reported to feel "pleasant." In contrast, the control group had a decline in their fitness and overall health. 
This study is of particular significance to our study because it suggests that clamping the exercise intensity at an RPE of 13 produces: 1) physiological responses within ACSM's Guidelines and 2) improvements in overall fitness and cardiovascular health. An RPE of 13 is approximately the same as the intensity perceived at the LP stage of the TT. Therefore, clamping exercise intensity to that of the intensity of the LP stage should produce physiological responses within ACSM's Guidelines and lead to improvement in overall fitness and cardiovascular health.

With the research conducted thus far, it has been concluded that: 1) exercise intensity can be prescribed using the TT, 2) the TT is a valid method of measuring physiological makers such as the VT and the LT and, 3) the TT is an appropriate method of measuring exercise intensity in healthy, sedentary, clinical, and athletic populations. However, it remains unclear as to what physiological effects occur when the exercise condition is held constant. All previous research on the TT has examined what exercise intensities are associated with each stage of the TT (e.g. absolute exercise intensity) and how physiological markers differ between them. What we are aiming to find with this study is what happens to exercise intensity, HR, and [HLa] if the exercise condition defined by the TT is held constant. This poses the question of our study; can the TT be used proactively to control exercise intensity below the LT and MLSS?

We hypothesize that: 1) If the TT is positive, exercise intensity will be less than the LT meaning lactate concentration will be constant during steady state exercise, 2) If the TT is equivocal, exercise intensity will approximate the MLSS meaning lactate will increase but then stabilize and, 3) If the TT is negative, 
exercise intensity will be greater than the MLSS meaning that progressive lactate accumulation will occur. 


\section{METHODS}

\section{Subjects}

Apparently healthy and well trained students $(n=16)$ aged 19 -26 volunteered and served as subjects. All subjects were screened with a Physical Activity Readiness Questionnaire (PAR-Q) to identify health problems that might contraindicate participation. The protocol, purpose, and risks of the study were thoroughly explained and each subject provided written informed consent. Approval from the University of Wisconsin-La Crosse Institutional Review Board for the Protection of Human Subjects was obtained prior to the study.

Table 1. Descriptive statistics of the subjects

\begin{tabular}{lllllll}
\hline Subjects & Age & Height & Weight & $\mathrm{VO}_{2} \max$ & $\mathrm{VO}_{2}$ at $\mathrm{VT}$ & $\mathrm{VO}_{2}$ at RCT \\
& $\begin{array}{lllll}\text { (years) } \\
(\mathrm{cm})\end{array}$ & $(\mathrm{kg})$ & $(\mathrm{ml} / \mathrm{kg} / \mathrm{min})$ & $(\mathrm{ml} / \mathrm{kg} / \mathrm{min})$ & $(\mathrm{ml} / \mathrm{kg} / \mathrm{min})$ \\
\hline Men: 8 & $21.6 \pm 1.4$ & $179.8 \pm 5.7$ & $77.6 \pm 10.9$ & $60.2 \pm 7.2$ & $41.2 \pm 9.7$ & $48.0 \pm 7.5$ \\
Women: 8 & $22.8 \pm 1.7$ & $168.4 \pm 6.2$ & $66.2 \pm 7.1$ & $49.7 \pm 4.8$ & $33.8 \pm 5.9$ & $42.6 \pm 6.7$ \\
\hline
\end{tabular}

\section{Procedures}

Each subject performed two incremental exercise tests on a motorized treadmill: 1 ) with measurement of respiratory gas exchange to measure $\mathrm{VT}$, RCT and $\mathrm{VO}_{2}$ max and, 2) without respiratory gas exchange to measure TT responses. On separate days, subjects performed four treadmill runs of 30 minutes or until exhaustion with instructions to 
maintain either: 1) a positive TT, represented by both LP and LP-1 2) a EQ TT, or 3) a NEG TT. Speed, HR, RPE and TT responses were measured during the last 30 seconds of each 2-minute segment of the 30-minute run and [HLa] was recorded at $0,10,20$, and 30 minutes; or at exhaustion if the subject could not continue. Based on the results of each subject's maximal incremental test with TT responses, we predetermined the speeds at which they would begin their steady state runs, representing their LP-1, LP, EQ, and NEG stages. The speed was adjusted every two minutes to maintain the clamped TT response. The order of the tests was randomized and there were at least 48 hours between tests.

During the last 30 seconds of each 2-minute stage, the subject recited aloud the Pledge of Allegiance (POA). When they were finished, the researcher asked the subject, “can you speak comfortably?” Depending on the subject's response and what steady state condition the subject was completing (LP-1, LP, EQ, or NEG), the treadmill speed was adjusted in order to maintain or achieve the desired TT response. During the LP-1 and LP TT runs, subjects were instructed to maintain a pace that allowed them to speak comfortably. If they answered "no" or "I'm not sure” to the question "can you speak comfortably?”, the researcher decreased the treadmill speed by $0.1 \mathrm{mph}\left(0.0447 \mathrm{~m} .^{\mathrm{s}-1}\right)$ at the beginning of the next segment. This was accomplished every two minutes until their TT response changed to “yes.” During the EQ TT run, the subject was instructed to maintain a pace at which they were still able to speak, but with difficulty. If the subject answered “yes” to the question “can you speak comfortably?” during the last 30 seconds of each 2-minute segment, the treadmill speed was increased by $0.1 \mathrm{mph}\left(0.0447 \mathrm{~m} . \mathrm{s}^{-1}\right)$ until their response changed to a "yes, but...” If the subject answered "no" to the 
question “can you speak comfortably?” during the last 30 seconds of each 2-minute segment, the treadmill speed was decreased by $0.1 \mathrm{mph}\left(0.0447 \mathrm{~m} . \mathrm{s}^{-1}\right)$ at the beginning of the next stage and every two minutes until their answer changed to a “yes, but...”. During the NEG TT run, the subjects were instructed to maintain a pace that prevented them from being able to speak comfortably. If their answer to the question "can you speak comfortably?” was “yes” or "yes, but...” during the last 30 seconds of each 2-minute segment, the researcher increased the treadmill speed by $0.1 \mathrm{mph}\left(0.0447 \mathrm{~m} \cdot \mathrm{s}^{-1}\right)$ until their answer changed to "no".

Prior to each 30 minute steady state run, all subjects completed the same warm-up. The incline was always at $1 \%$ to simulate running outside (Jones \& Doust, 1996). The warm up was five minutes in duration and began at $1.34 \mathrm{~m} \cdot \mathrm{s}^{-1}(3 \mathrm{mph})$. At one minute, the speed increased to $1.79 \mathrm{~m} \cdot \mathrm{s}^{-1}(4 \mathrm{mph})$, and at two minutes, the speed increased again to $2.24 \mathrm{~m} \cdot \mathrm{s}^{-1}(5 \mathrm{mph})$ where it remained for the rest of the warm up. Once the five minute warm up was completed, the subject straddled the treadmill for a 2-minute rest. Approximately 45 seconds prior the start of the 30-minute run, the first lactate sample was taken, referred to as the lactate level at 0 -minutes. At 0, 10, 20, and 30 minutes, [HLa] was measured. When approaching 10, 20, and 30 minutes, the researcher counted down and instructed the subject to straddle the treadmill when the time mark was reached. [HLa] levels were measured while the subject was straddling the treadmill. Each measurement was obtained within 30 seconds and as soon as the measurement was completed, the subject continued their run. Speed, HR, and RPE continued to be recorded every two minutes until the 30 minutes were completed or the subject could not run anymore. Test time was not paused for the lactate readings since all were obtained 
within 30 seconds, and since we reasoned that the energy cost of getting back on the treadmill was more or less equivalent to continuing to run.
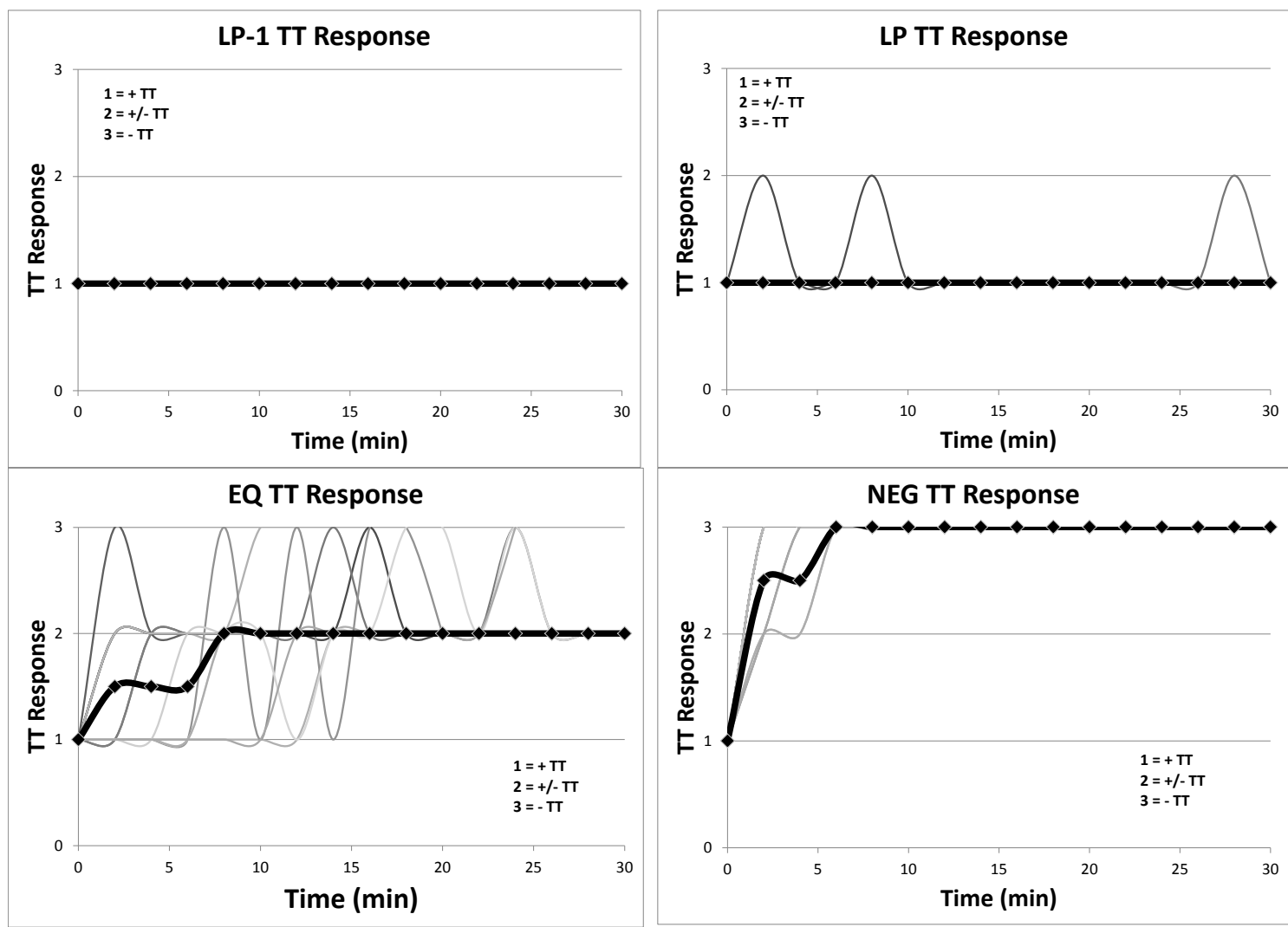

Figure 1. TT responses across the 30 minute time trials (LP-1, LP, EQ, NEG)

\section{Statistical Analysis}

Results of this study were observational and aside from calculating the means and standard deviations, additional statistical analyses were not performed. 


\section{RESULTS}

Our hypotheses were that: 1) If the TT is positive (LP-1 or LP) exercise intensity would be less than the LT meaning lactate concentration will be constant, 2) If the TT is EQ, exercise intensity would be below the MLSS meaning lactate would increase but then stabilize and, 3) If the TT is NEG, exercise intensity would be greater than the MLSS meaning that progressive lactate accumulation would occur, were supported. The LP-1 and LP stages generally produced intensities compatible with accepted training intensity for healthy adults, while the EQ and NEG stages produced intensities compatible with training in athletes.

The first aspect investigated when analyzing the data was comparing the results from the maximal Gas Exchange (GE) test with the results from the maximal Talk Test (maxTT). The measurements recorded in both maximal tests (HR, TT response, and RPE) were very similar. In Figure 2, we compared the Ventilatory Equivalent for Oxygen (VentEq) with the TT responses. The VentEq is staggered through the first half of the incremental test but then starts to rise abruptly approximately at a speed of $4 \mathrm{~m} / \mathrm{sec}$. At nearly the same time, the TT responses are changed from a positive result to an equivocal result, representing VT. At approximately $4.7 \mathrm{~m} / \mathrm{sec}$, the slope of the VentEq rises abruptly again. Meanwhile the TT responses change from an equivocal result to a negative result, representing the RCT. The TT response is consistently delayed by about one stage before it adjusts to represent the correct physiologic changes occurring. This is 
what we expected because subjects often do not realize how they are feeling subjectively at exactly the same time as their objective values change. There is a delay simply due to the subjects' perception of the change in intensity. The same results were seen in the HR and RPE comparisons (Figure 2). The HR's in both tests correlated very closely with one another while the RPE values were still correlated by not quite as closely. The RPE values in the maxTT were consistently lower than the RPE values from the GE test. We believe this to be due to the fact that having the mouthpiece in is uncomfortable for subjects, causing them to perceive their activity at any given time harder than if they were not wearing it. This belief is supported by the observation that the majority of subjects completed a longer duration (in minutes) during their maxTT $(20.9 \pm 4.73)$ than their $\mathrm{VO}_{2} \max$ test $(20.3 \pm 4.53)$.
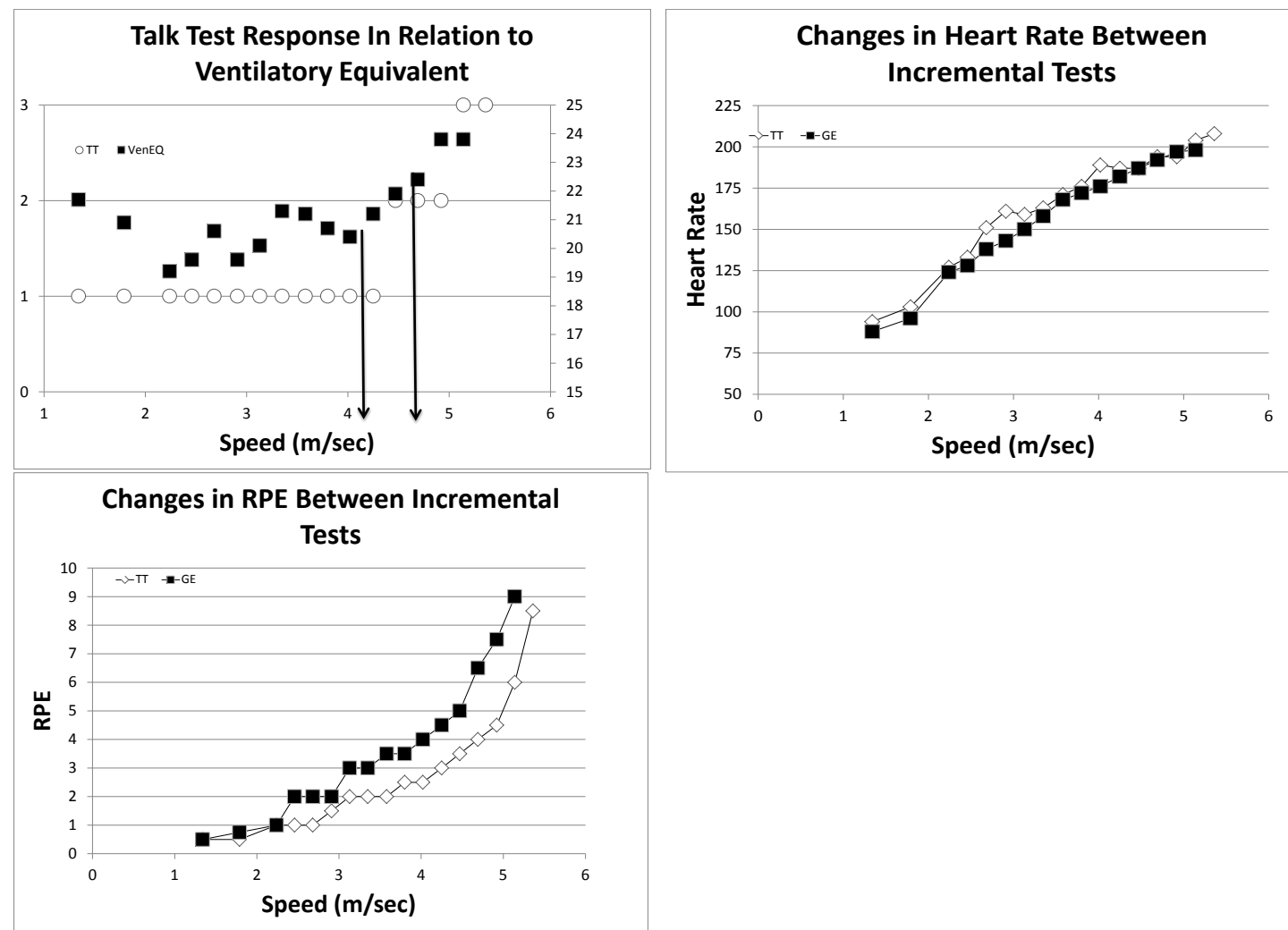

Figure 2. Physiological marker comparisons between maximal Gas Exchange (GE) and maximal Talk Test (TT) 
Steady State conditions were achieved in the LP-1 and LP stages. All six of the measured values (speed, HR, RPE, [HLa], \%HRR, and TT responses) remained relatively constant across the 30-minute time trial. In addition, all 16 subjects successfully completed the 30 minutes in both the LP-1 and LP runs. As represented in the 4-part graphs, the speed (Figure 3) did not need to be greatly adjusted throughout the time trial. In both the LP-1 and LP runs, from the first stage through the last, each subject was able to maintain a positive TT response with little to no adjustments in the speed.
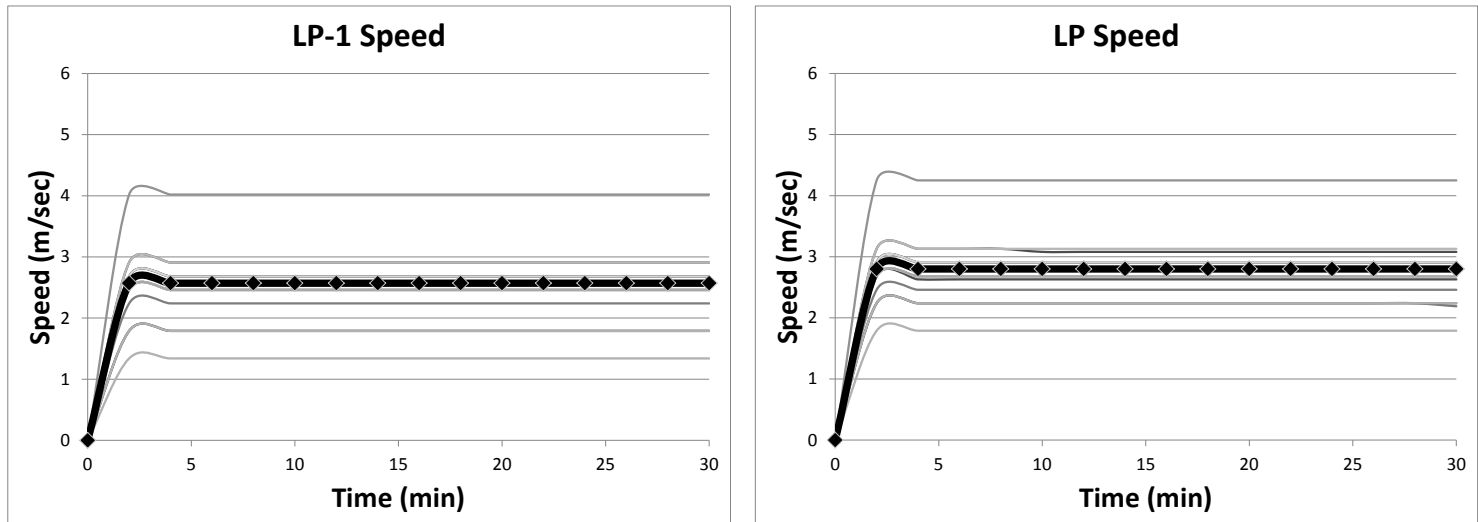

Figure 3. Changes in speed across the 30-minute time trials (LP-1 and LP)
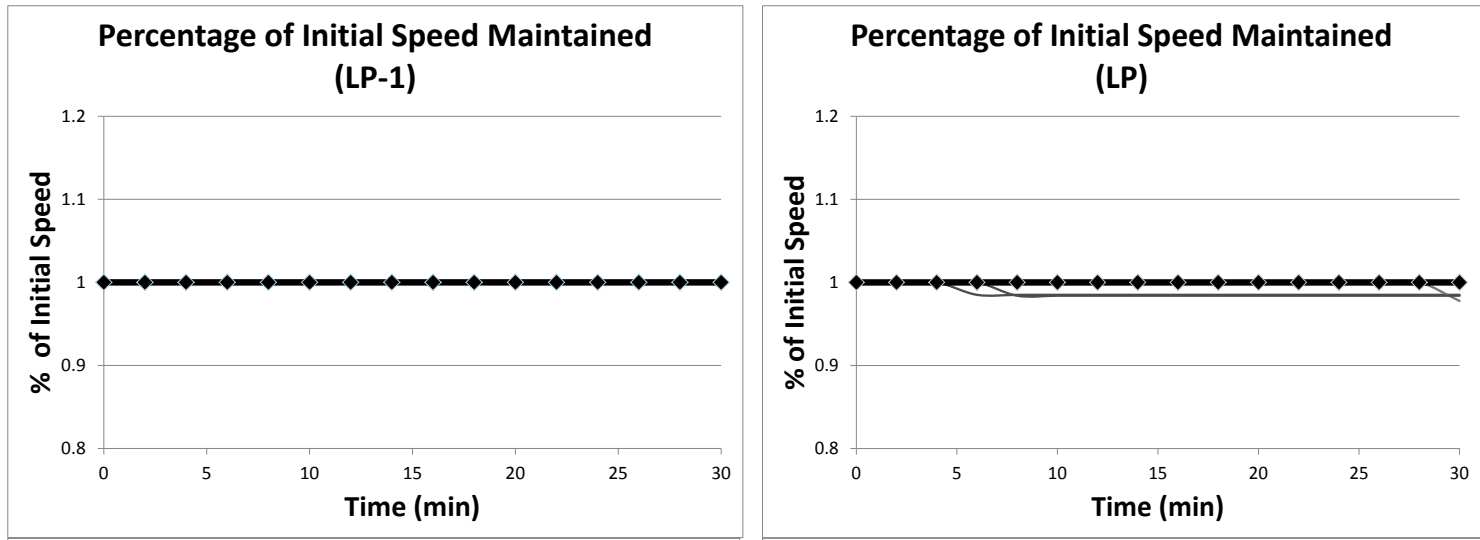

Figure 4. Percentage of initial speed maintained during each 2-minute segment of the 30minute runs (LP-1 and LP) 
The HR's seen in the LP-1 and LP stages remained relatively constant throughout the 30-minute time trial as well (Figure 5). There was no meaningful deviation in the HR's at each stage. The only noticeable differences seen were the slight decrease in HR immediately after 10 and 20 minutes. This was due to the fact that at 10 and 20 minutes, the subject was straddling the treadmill for up to 30 seconds in order to give a lactate sample. This brief pause was enough time for the HR's to start to decrease. This change is easily seen on the graphs as well as its consistent return to normal by approximately the next stage. Each subjects’ \%HRR remained similarly constant throughout the 30 minutes with the same temporary decreases immediately following 10 and 20 minutes (Figure 6). Naturally, the HR's and \%HRR in the LP stage were higher because the speed was faster than the speed in the LP-1 stage. The transparent boxes in each of the \%HRR graphs represent ACSM's recommendations for \%HRR during exercise for healthy adults (5085\%). In both LP-1 and LP, each subjects' \%HRR throughout the whole 30 minutes were within the recommended guidelines.
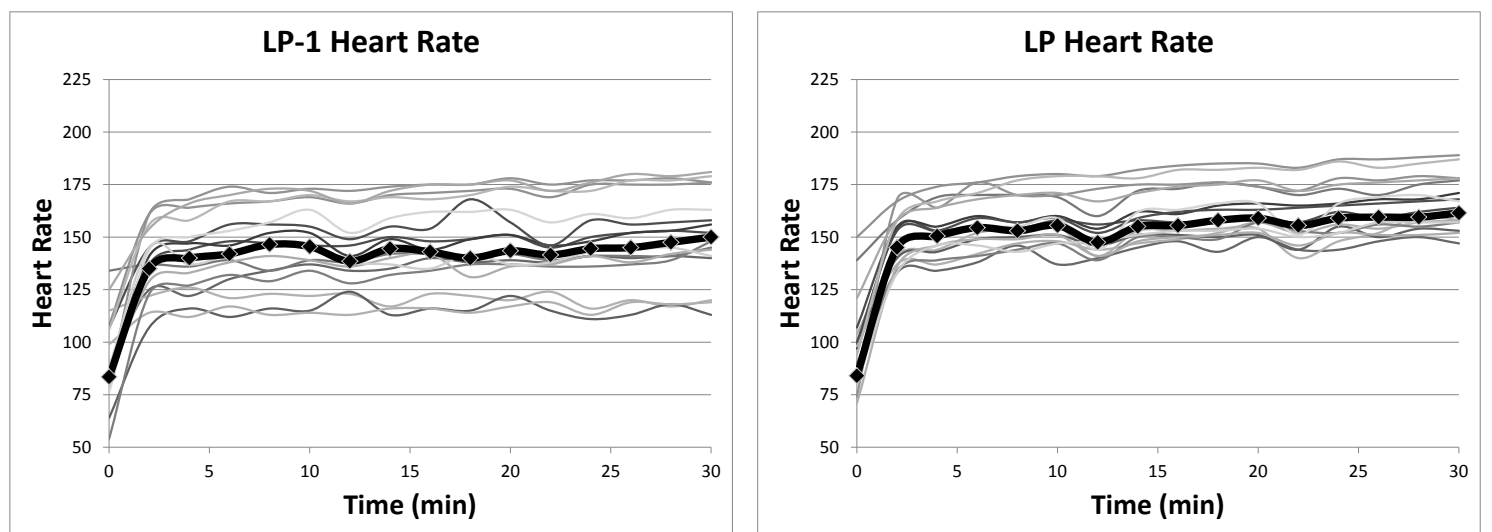

Figure 5. HR fluctuations during the 30-minute time trials (LP-1 and LP) 

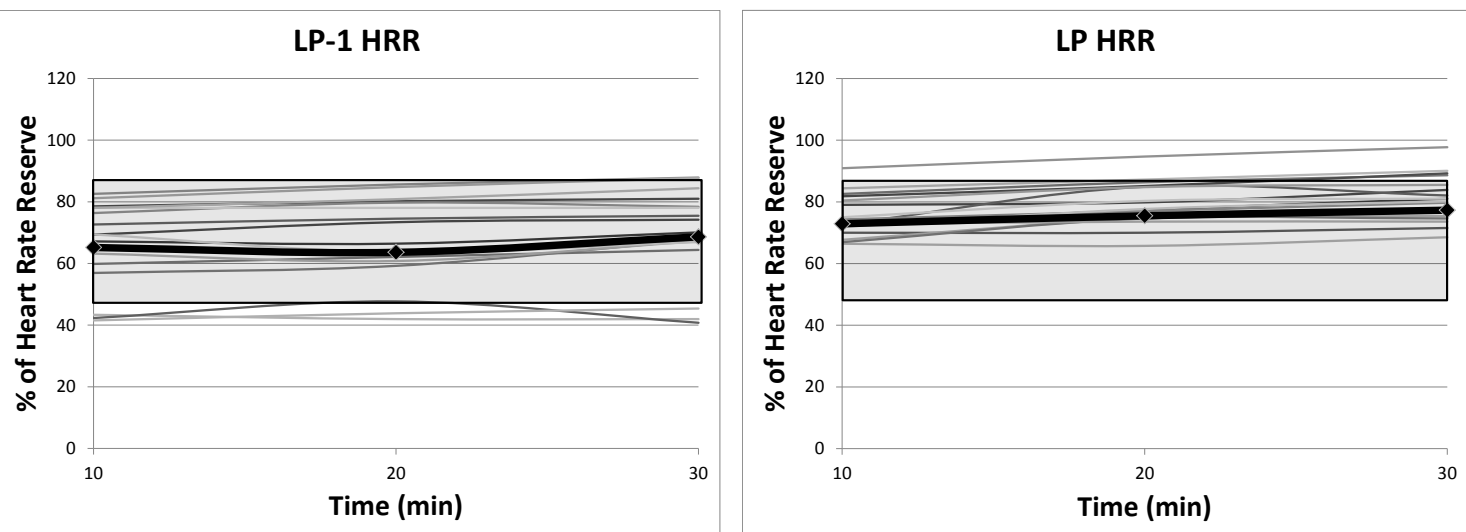

Figure 6. \%HRR fluctuations during the 30-minute time trials (LP-1 and LP)

The RPE responses were very similar to the HR and \%HRR reserve graphs. The RPE did not deviate much across the 30-minute time trial and the values in the LP run were consistently higher than in the LP-1 run, representing the increased intensity (Figure 7).
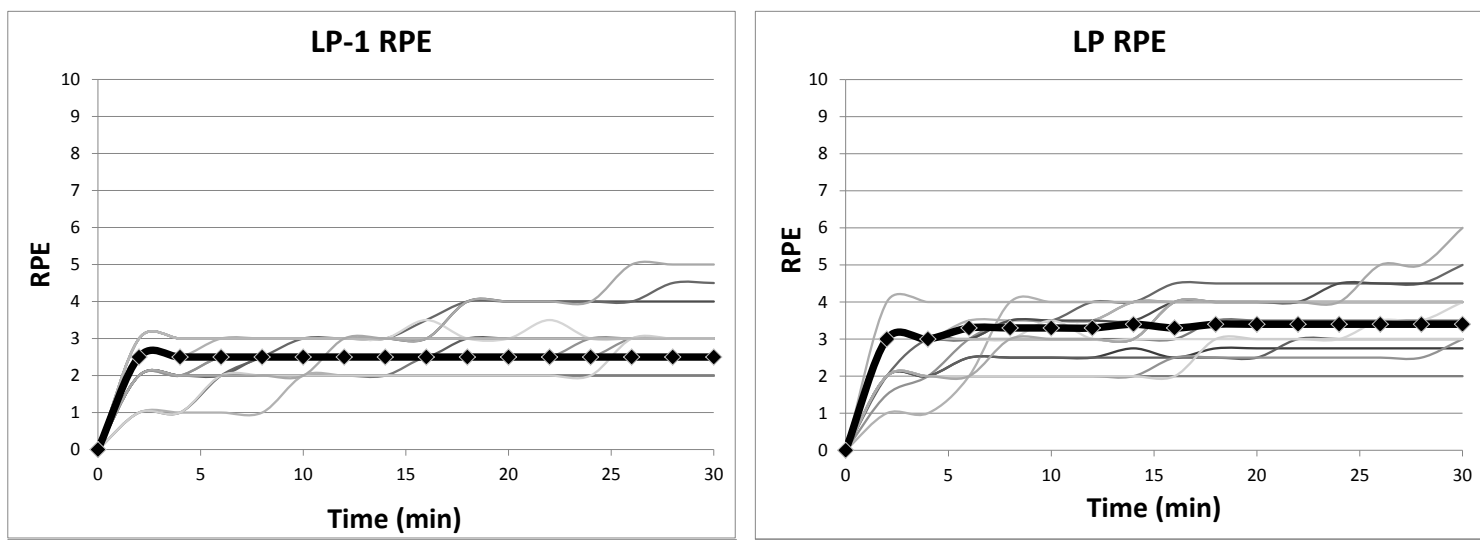

Figure 7. RPE fluctuations during the 30-minute time trials (LP-1 and LP)

The [HLa] showed the same trend. Each subject’s [HLa] remained relatively constant across the 30 minutes. In fact, represented by the average line in the LP-1 graph, [HLa] actually decreased slightly from 0 to 30 minutes (Figure 8 ). Although the average lines are only representative of the two subjects able to finish 30 minutes in all four stages, the individual lines also show this trend. For several subjects, this was due to 
the fact that the ending warm-up speed of $2.24 \mathrm{~m} / \mathrm{sec}(5 \mathrm{mph})$ was faster than several of the subject's predetermined speeds during the 30 minute time trial. Similar to the HR and RPE graphs, [HLa] reached higher values at 10, 20, and 30 minutes during the LP run representing the increased intensity from the LP-1 run.
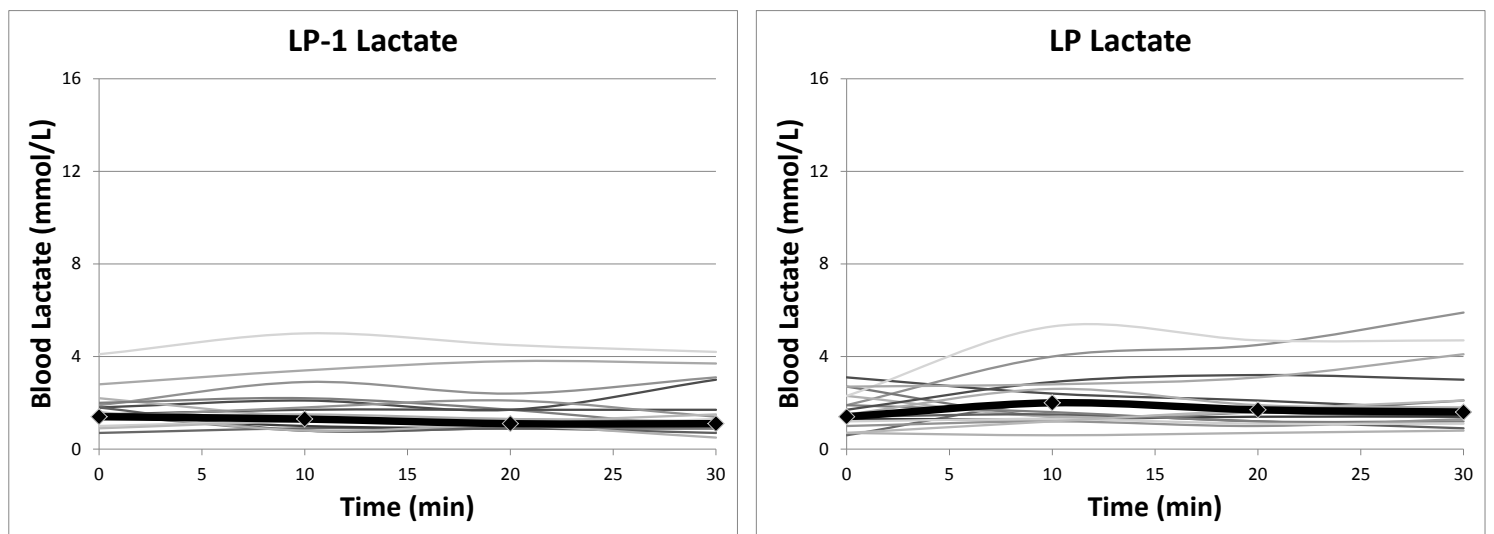

Figure 8. [HLa] fluctuations during the 30-minute time trials (LP-1 and LP)

While the evidence demonstrates that steady state conditions were successfully achieved during the LP-1 and LP runs, a possible limitation to the TT may have affected the results. Each subject was given the same explanation and definition of the TT and its responses. However, the accuracy of the TT directly depends on the subject's understanding and willingness to answer honestly. If the subject claimed they could speak comfortably when really they could not, their exercise capacity was likely overestimated and if the subject claimed they could not speak comfortably when they really could, their exercise capacity was likely underestimated. This complication seemed to occur mostly at the EQ and NEG stages because some subjects struggled with either the concept of the TT and/or the fact that they could not speak comfortably for as long as they had hoped. This complication was not as apparent within the LP-1 and LP stages as the speed was only reduced by the researcher was when the subject's TT 
response did not match the response of the desired clamped intensity. Regardless of whether the subjects answered correctly and truthfully during their maxTT, the opportunity to adjust the speed (as the researcher) was severely limited by the subject's initial responses. For example, several subjects (in the researcher’s opinion) underestimated their ability to speak comfortably at the given stages. These faulty responses were only consequential in the EQ and NEG stages because if the subject underestimated their ability to speak comfortably on their maxTT, their TT responses during their LP-1 and LP runs were positive when they could have potentially been positive at a higher speed. If, during the LP-1 and LP runs, the subject underestimated their ability to speak, their response to the question, “can you speak comfortably?” at the end of the first 2-minute stage was "yes”, warranting no change in speed by the researcher according to protocol. However, if the subject either under or overestimated their ability to speak comfortably at their EQ and NEG stages, this warranted more deviation in speed by the researcher because the speed could be increased or decreased, as opposed to just decreased if they answered "no" during the LP-1 and LP stages.

The combined results of speed, HR, RPE, [HLa], \%HRR, and TT responses at the LP-1 and LP stages were representative of steady state conditions in all 16 subjects. With lactate specifically, our hypothesis that intensities associated with the LP and LP-1 stages would be below the LT was supported because the [HLa] remained stable throughout the entire 30 minutes.

Steady state conditions were not achieved during the EQ and NEG stages. This is most obviously represented by the fact that not all subjects were able to successfully complete the 30 minutes. Only 13 and 2 subjects were able to complete the EQ and NEG 
runs respectively (Figures 9 and 10). Due to the limitation mentioned earlier about the ability of the researcher to adjust the speed (increase or decrease) lead to an increased amount of deviation from the starting speeds in each subject. The EQ run had the most speed changes than any other stage. The NEG run had more speed changes than the LP-1 and LP runs but less than the EQ run. We believe that this is due to the similar fact that the opportunity to change the speed during the NEG run is dependent on an answer of "yes" or "yes but" meaning the only option in adjusting the speed would be to increase it. This is the same limitation we observed with the LP-1 and LP stages because the only option in adjusting the speed was to decrease it. In the EQ run however, speed adjustments could be made in either direction leading to a greater amount of total deviation from the initial speed (Figures 11 and 12).

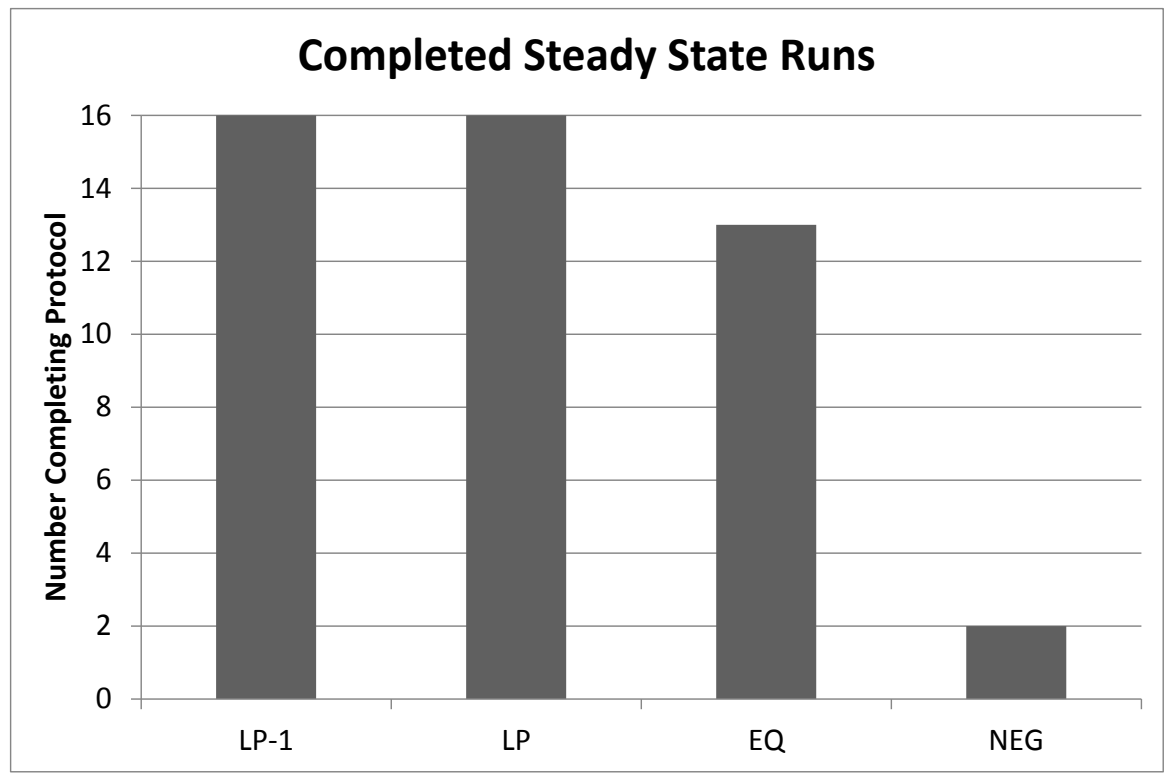

Figure 9. Number of subjects who completed each 30-minute time trial 


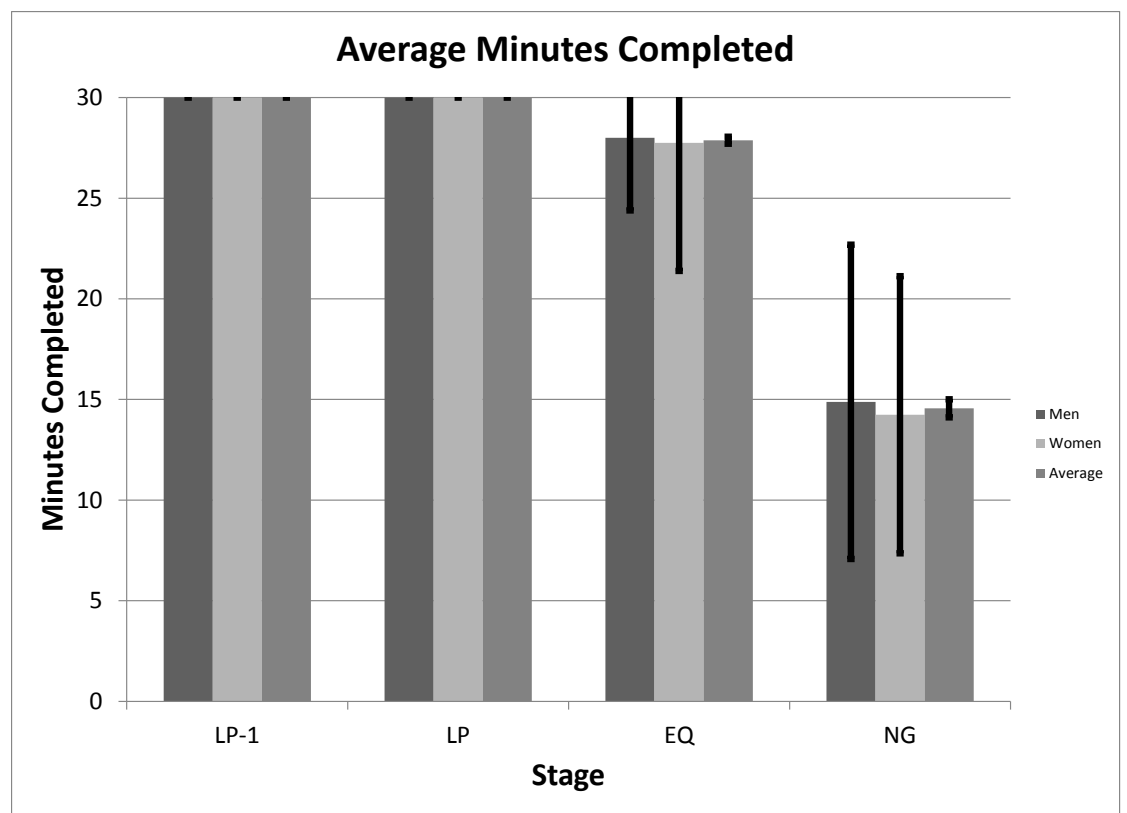

Figure 10. Average time (in minutes) in completion of each 30-minute time trial
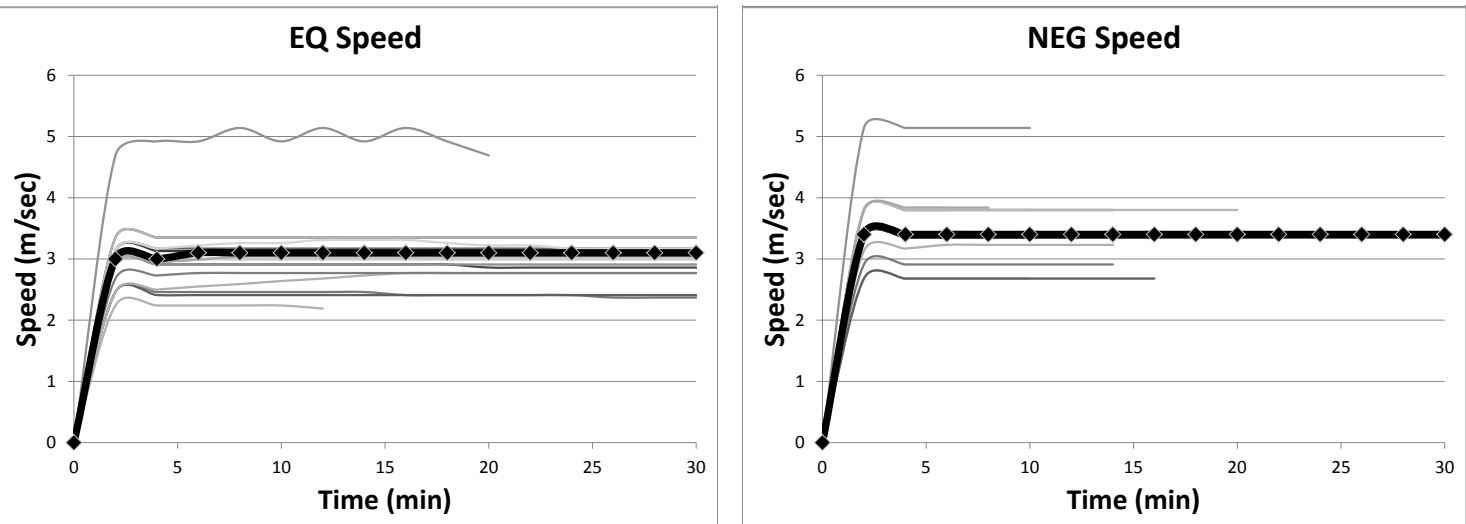

Figure 11. Speed fluctuations during each 30-minute time trial (EQ and NEG) 

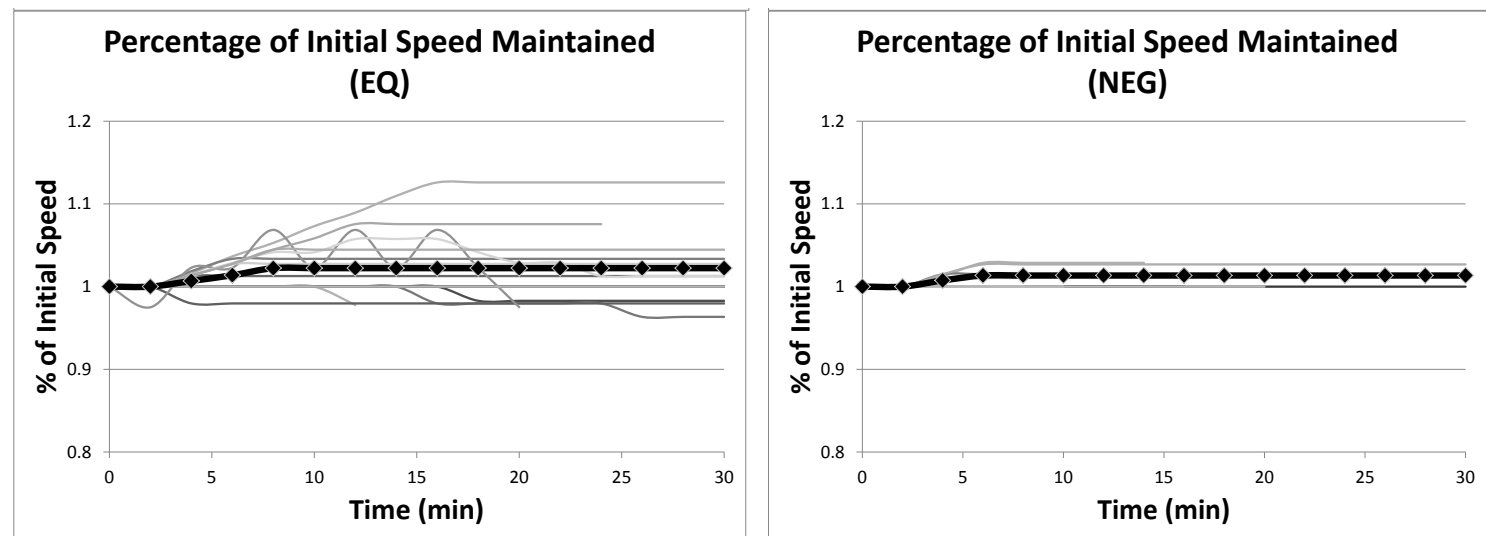

Figure 12. Percentage of initial speed maintained every 2-minute segment during each 30- minute run (EQ and NEG)

HR responses during the EQ and NEG stages were similar the HR responses seen in the LP-1 and LP stages with a few exceptions: 1) the initial increases in HR were larger than the increases seen in the LP-1 and LP stages because the speeds were faster and the intensities were higher and 2) HR responses remained less stable across the 30 minutes in both the EQ and NEG stage runs represented by a continual general increase in HR from 0 to 30 minutes (with a larger continual increase in the NEG run due to the higher intensity and being above LT). The same temporary HR decreases were seen at 10 and 20 minutes as well as the prompt return to normal by the start of the following stage (Figure 13). 

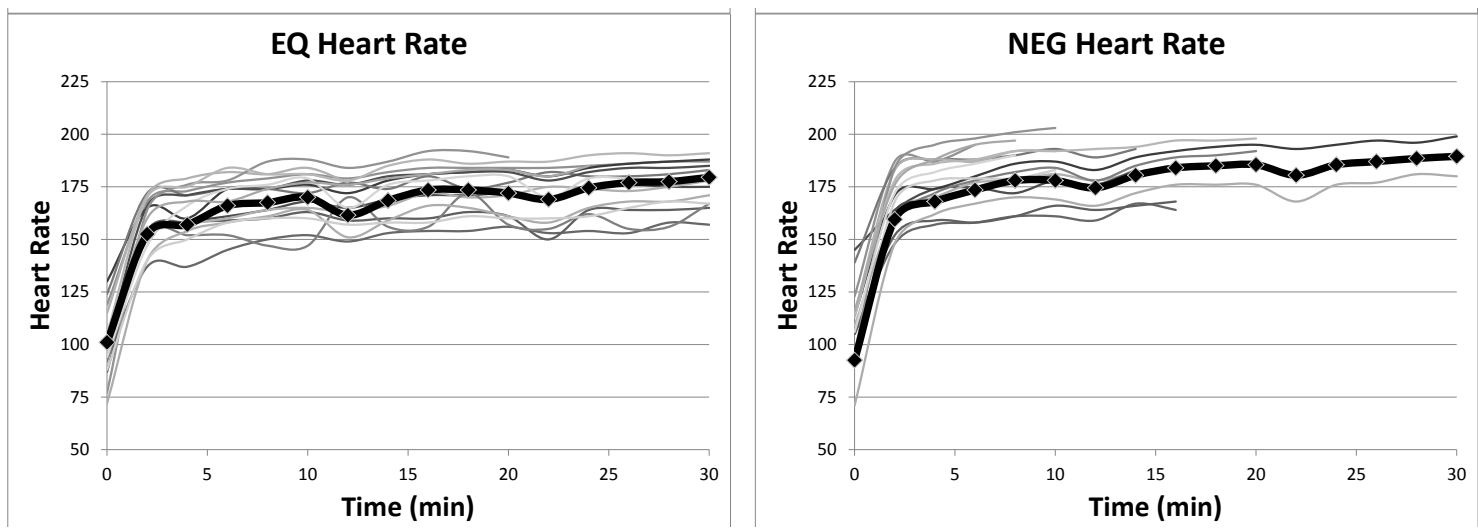

Figure 13. HR fluctuations during each 30-minute time trial (EQ and NEG)

Using the same ACSM recommendations of \%HRR (represented by the transparent boxes) HRR did not stay within the recommended $50-85 \%$ in either the EQ or NEG stage runs. During the EQ run, HR's began to exceed the recommendations at approximately 25 minutes and during the NEG run, the beginning HRR's exceeded the recommendations and therefore continued to do so throughout the entire 30 minute time trial (Figure 14). Similarly, RPE responses began higher and continued to rise (as opposed to stabilizing as they did during the LP-1 and LP stages) throughout the 30 minutes, further suggesting the subjects to be at (for the EQ) or above (for the NEG) their VT and LT (Figure 15). 

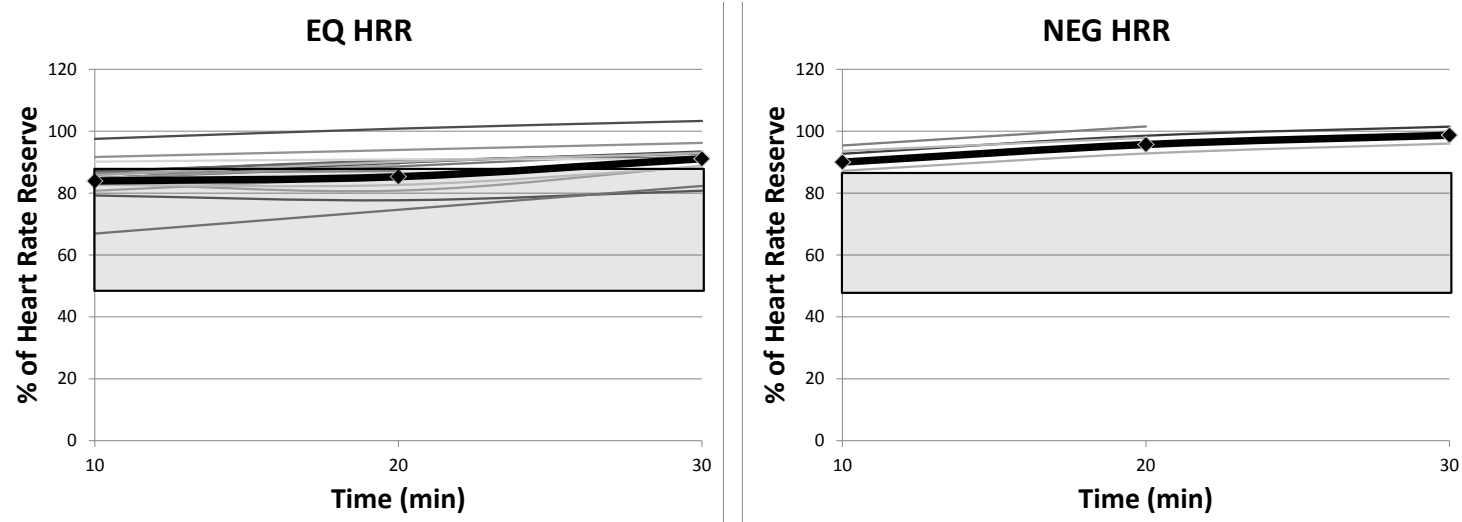

Figure 14. \%HRR fluctuations during each 30-minute time trial (EQ and NEG)
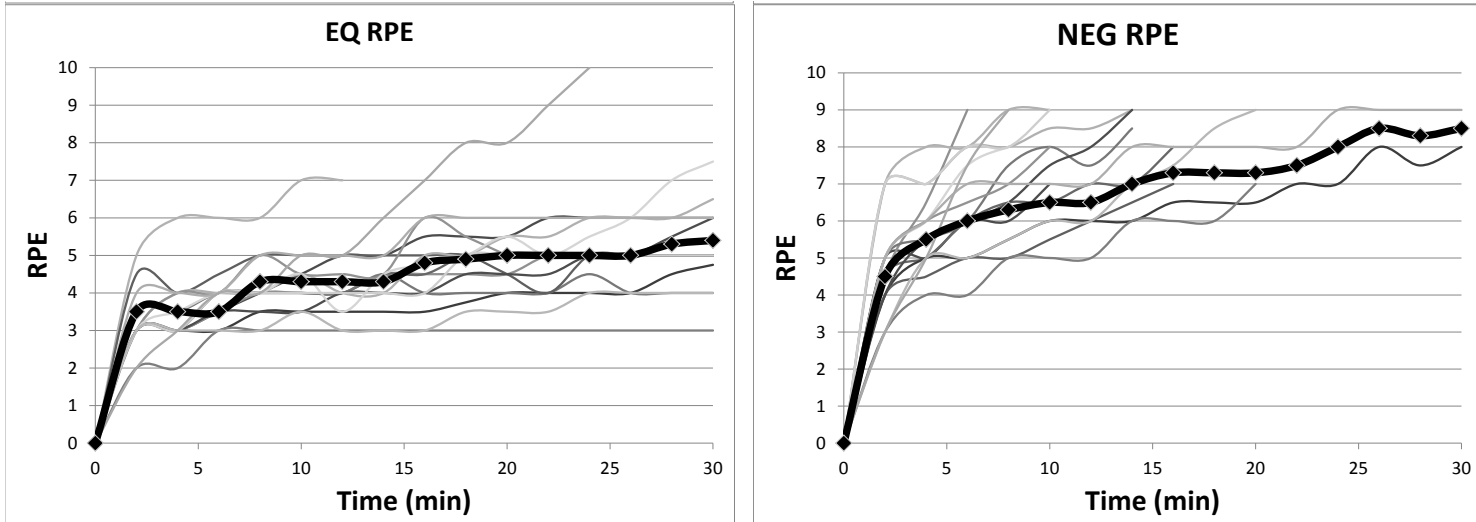

Figure 15. RPE fluctuations during each 30 minute time trial (EQ and NEG)

The [HLa] graphs of the EQ and NEG stages also support our hypothesis because the [HLa] levels across the subject pool 1) began at higher values, 2) continued to rise longer into the 30-minute time trials, 3) eventually stabilized by the end of the 30 minutes in the EQ run, and 4) continued to rise throughout the entire 30 minutes during the NEG run (Figure 16). These combined observations support our prediction that: 1) by clamping the TT response at an intensity associated with the EQ stage, exercise intensity would be below the Maximal Lactate Steady State (MLSS) meaning [HLa] accumulation would rise but then stabilize and 2) by clamping the TT response at an intensity associated with the NEG stage, exercise intensity would be above the MLSS meaning that [HLa] 
accumulation would initially occur and continue to do so throughout the entire 30 minutes.
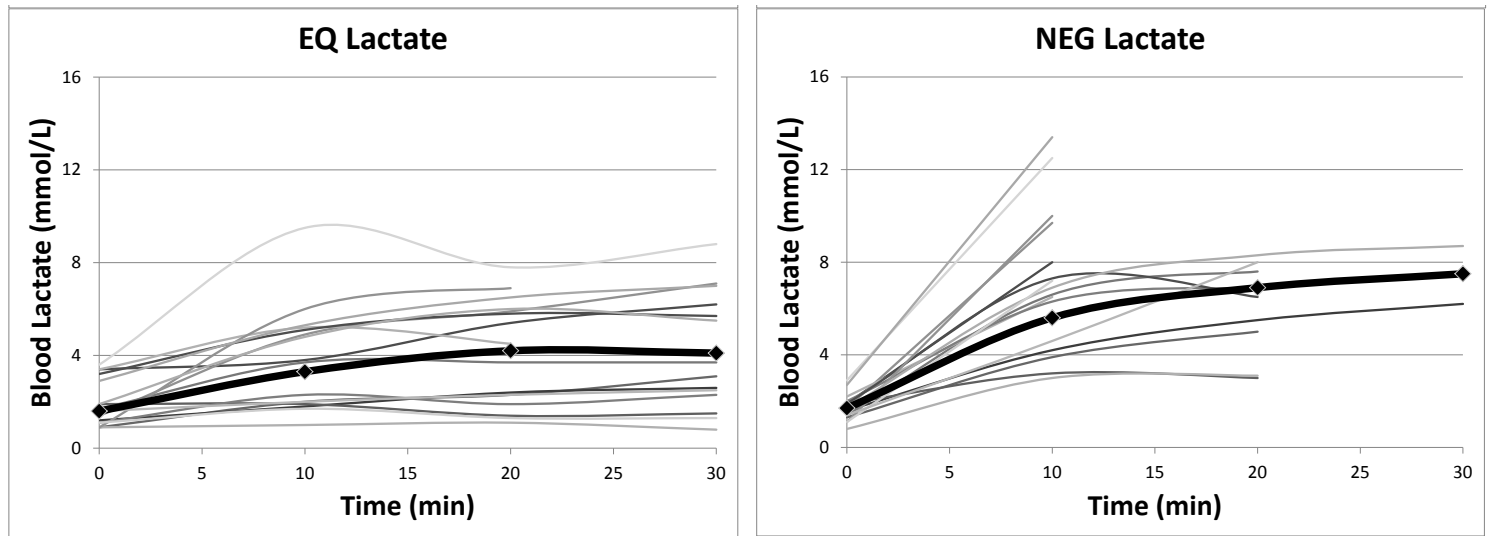

Figure 16. [HLa] fluctuations during each 30-minute time trial (EQ and NEG) 


\section{DISCUSSION}

When the TT was clamped, steady state conditions were achieved at the LP-1 and LP stages. All six measured conditions (speed, HR, RPE, [HLa], \%HR reserve, and TT responses) remained stable across the 30-minute runs. None of the six conditions had to be manipulated in order to achieve and maintain steady state conditions. The average \%HRR achieved during the LP-1 and LP runs was within ACSM recommendations for exercise intensity (50-85\% HRR).

There was no evidence of steady state conditions in the EQ and NEG stages. Not all of the 16 subjects were able to complete the EQ (13 of 16) and NEG (2 of 16) runs. All six measurements (speed, HR, RPE, [HLa], \%HR reserve, and TT responses), recorded responses during the EQ stage run were higher (than LP-1 and LP runs). The recorded values in the NEG run were even higher than in the EQ run and continued to rise throughout the entire trial. These observations support the findings that steady state conditions were not met during the EQ and NEG runs. The \%HRR during EQ was within ACSM guidelines until approximately 25 minutes but exceeded 85\% HRR by 30

minutes. During the NEG run, HR exceeded the recommended 85\%HRR throughout the entire 30 minutes.

[HLa] remained stable and near resting values throughout 30 minutes in both LP1 and LP. In EQ, [Hla] rose to higher levels but stabilized between 20-30 minutes. This indicates that the EQ condition represented an intensity which is at or below the MLSS. 
In the NEG condition, [HLa] rose progressively throughout the entire run, with only two subjects able to complete 30 minutes. This indicates that during NEG exercise intensity is above MLSS.

The average lines on each of the graphs are representative of the data from the two subjects that successfully completed 30 minutes in all four runs (LP-1, LP, EQ, and NEG).

\section{Conclusion}

The data suggest that TT is a valid technique for prescribing exercise intensity. TT responses (positive, equivocal, and negative) accurately correlate with exercise intensities below, at/near, and above the VT and LT. These data indicate that when TT responses are clamped, that predictable levels of exercise intensity are achieved that are within accepted parameters for exercise training in both healthy individuals and athletes. 


\section{REFERENCES}

American College of Sports Medicine, (2010). ACSM's Guidelines for Exercise Testing and Prescription $8^{\text {th }}$ edition. Maryland: Lippincott Williams \& Wilkins for the American College of Sports Medicine.

Borg, G. Borg's Perceived Exertion and Pain Scales. Champaign, IL: Human Kinetics; 1998.

Brawner, C. A., Vanzant, M. A., Ehrman, J. K., Foster, C., Porcari, J. P., Kelso, A. J., \& Keteyian, S. J. (2006). Guiding exercise using the talk test among patients with coronary artery disease. Journal of Cardiopulmonary Rehabilitation, 26, 72-75.

Cannon, C., Foster, C., Porcari, J. P., Skemp-Arlt, K. M., Fater, D. C. W., \& Backes, R. (2004). The talk test as a measure of exertional ischemia. American Journal of Medicine and Sports, 6, 52.

Dehart-Beverly, M., Foster, C., Porcari, J. P., Fater, D. C. W., \& Mikat, R. P. (2000). Relationship between the talk test and ventilatory threshold. Clinical Exercise Physiology, 2, 34-38.

Eston, R. (2012). Use of ratings of perceived exertion in sports. International Journal of Sports Physiology and Performance, 7, 175-182.

Foster, C., Porcari, J. P., Anderson, J., Paulson, M., Smaczny, D., Webber, H., \& Doberstein, S. T. (2008). The talk test as a marker of exercise training intensity. Journal of Cardiopulmonary Rehabilitation and Prevention, 28, 24-30

Foster, C., Porcari, J. P., Gibson, M., Wright, G., Greany, J., Talati, N., \& Recalde, P. (2009). Translation of submaximal exercise test responses to exercise prescription using the talk test. Journal of Strength and Conditioning Research, 23(9), 2425-2429

Foster, C., Porcari, J. P., de Koning, J. J., Bannwarth, E., Condello, G., Galamback, K., Gibson, M, Lueck, J., Rodriguez-Marroyo, J. A., \& Walraven, L. (2012). Exercise training for performance and health. Dtsch Z Sportmed, 63, 69-74.

Jeans, E. A., Foster, C., Porcari, J. P., Gibson, M, and Doberstein, S. (2011). Translation of exercise testing to exercise prescription using the talk test. Journal of Strength and Conditioning Research, 25(3), 590-596. 
Jones, A. M. \& Doust, J. H. (1996). A 1\% treadmill grade most accurately reflects the energetic cost of outdoor running. Journal of Sports Sciences, 14(4), 321-327.

Katch, V., Weltman, A., Sady, S., \& Freedson, P. (1978). The validity of the relative percent concept for equating training intensity. European Journal of Applied Physiology and Occupational Physiology, 39(4), 219-227.

Loose, B. D., Christensen, A. M., Smolcyzyk, J. E., Roberts, K. L., Budziszewska, A., Hollatz, C. G., \& Norman, J. F. (2012). Consistency of the counting talk test for exercise prescription. Journal of Strength and Conditioning, 26(6), 1701-1707.

Meckel, Y., Rotstien, A., \& Inbar, O. (2002). The effects of speech production on physiologic responses during submaximal exercise. Medicine \& Science in Sports \& Science, 34(8), 1337-1343.

Mezzani, A., Hamm, L. F., Jones, A. M., McBride, P. E., Moholdt, T., Stone, J. A., Urhausen, J. P., \& Williams, M. A. (2012). Aerobic exercise intensity assessment and prescription in cardiac rehabilitation. Journal of Cardiopulmonary Rehabilitation and Prevention, 32, 327-350.

Norman, J. F., Kracl, D., Parker, D., \& Richter, A. (2002). Comparison of the counting talk test and heart rate reserve methods for estimating exercise intensity in healthy young adults. Journal of Exercise Physiology Online, 5, 15-22.

Norman, J. F., Hopkins, E., \& Crapo, E. (2008). Validity of the counting talk test in comparison with standard methods of estimating exercise intensity in young healthy adults. Journal of Cardiopulmonary Rehabilitation and Prevention, 28, 199-202.

Parfitt, G., Evans, H., \& Eston, R. (2012). Perceptually regulated training at RPE13 is pleasant and improves physical health. Medicine \& Science In Sports \& Exercise, 44(8), 1613-1618.

Persinger, R., Foster, C., Gibson, M., Fater, D. C. W. \& Porcari, J. P. (2004). Consistency of the talk test for exercise prescription. Medicine \& Science in Sports \& Exercise, 36(9) 1632-1636.

Quinn, T. J., \& Coons, B. A. (2011). The talk test and its relationship with the ventilatory and lactate thresholds. Journal of Sports Sciences, 29(11), 1175-1182

Recalde, P. T., Foster, C., Skemp-Arlt, K. M., Fater, D. C. W., Neese, C. A., Dodge, C., \& Porcari, J. P. (2002). The 'talk test' as a simple marker of ventilatory threshold. South Africa Sports Medicine, (9) 5-8. 
Rodriguez-Marroyo, J. A., Villa, G., Garcia-Lopez, J., \& Foster, C. (2012). Relationship between the talk test and ventilatory threshold in well-trained cyclists.

doi:10.1519/JSC.0b013e3182736af3

Scharhag-Rosenberger, F, Meyer, T., Gassler, N, Faude, O., \& Kindermann, W. (2009). Exercise at given percentages of VO2max: Heterogeneous metabolic responses between individuals. Journal of Science and Medicine in Sport, 13, 74-79.

Voelker, S. A., Foster, C., Porcari, J. P., Skemp, K. M., Brice, G., \& Backes, R. (2002). Relationship between the talk test and ventilatory threshold in cardiac patients. Clinical Exercise Physiology, 4(2), 120-123.

Zanettini, R., Centeleghe, P., Franzelli, C., Mori, I., Benna, S., Penati, C. and Sorlini, N. (2012). Validity of the talk test for exercise prescription after myocardial revascularization. European Journal of Preventative Cardiology, 20(2), 376-382. 


\section{APPENDIX A}

PAR-Q 
(A Questionnaire for People Aged 15 to 69)

Regular physical activity is fun and healthy, and increasingly more people are starting to become more active every day. Being more active is very safe for most people. However, some people should check with their doctor before they start becoming much more physically active.

If you are planning to become muxh more physicaly active than you are now, start by answering the seven questions in the box below. If you are between the ages of 15 and 69 , the PAR-Q will tell you if you should check with your doctor before you start. If you are over 69 years of age, and you are not used to being very active, check with your doctor.

Common sense is your best guide when you answer these questions. Please read the questions carefully and answer each one honesty: check YES or NO.

\begin{tabular}{|c|c|c|c|}
\hline YES & NO & & \\
\hline$\square$ & $\square$ & 1. & $\begin{array}{l}\text { Has your doctor ever said that you have a heart condition and that you should only do physical activity } \\
\text { recommended by a doctor? }\end{array}$ \\
\hline$\square$ & $\square$ & 2. & Do you feel pain in your chest when you do physical activity? \\
\hline$\square$ & $\square$ & 3. & In the past month, have you had chest pain when you were not doing physical activity? \\
\hline$\square$ & $\square$ & 4. & Do you lose your balance because of dizziness or do you ever lose consciousness? \\
\hline$\square$ & $\square$ & 5. & $\begin{array}{l}\text { Do you have a bone or joint problem (for example, back, knee or hip) that could be made worse by a } \\
\text { change in your physical activity? }\end{array}$ \\
\hline$\square$ & $\square$ & 6. & $\begin{array}{l}\text { Is your doctor currently prescribing drugs (for example, water pills) for your blood pressure or heart con- } \\
\text { dition? }\end{array}$ \\
\hline$\square$ & $\square$ & 7. & Do you know of any other reason why you should not do physical activity? \\
\hline 15 & & & YES to one or more questions \\
\hline & & & $\begin{array}{l}\text { Tak with your doctor by phone or in person BEFORE you start becoming much more physically active or BEFORE you have a ftress appraisal. Tel } \\
\text { your doctor about the PAR-Q and which questions you answered YES. }\end{array}$ \\
\hline ansv & & & 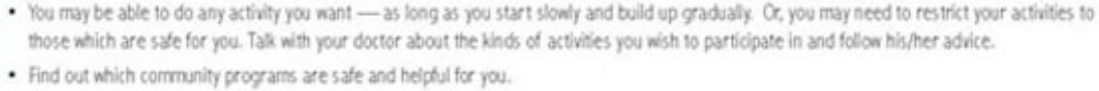 \\
\hline
\end{tabular}

\section{NO to all questions}

If you answered 10 honestly to all PMR-Q questions, you can be reasonably sure that you can:

- start becoming much more physically active - begin slowly and bulld up gradaaly. This is the

safest and easiest way to go

- take part in a fitness appraisal - this is an ocelent nay to deternine your basic finess so that you can plan the best way for you to five actively, it is also highly recormended that you have your bicod pressure evaluated. If your readng is over $144 / 94$, tak with your doctor before you start becoring much more phrikilly active

DELAY BECOMING MUCH MORE ACTIVE:

- If you are not feeling well because of a temporary iliness such as a cold or a fever - wat untl you feel better; or

- I you are or may be pregrant - takk to your doctor betore you start beroming more active.

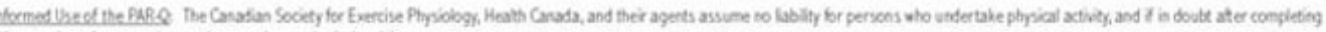

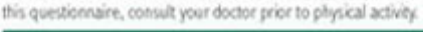

\section{No changes permitted. You are encouraged to photocopy the PAR-Q but only if you use the entire form.}

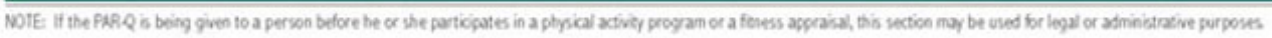

"T have read, understood and completed this questionnaire. Any questions I had were answered to my full satisfaction."

Nus

soutur

SOMT: OF PM⿻

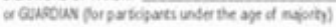

autf

Note: This physical activity clearance is valid for a maximum of 12 months from the date it is completed and becomes invalid if your condition changes so that you would answer YES to any of the seren questions. 
APPENDIX B

INFORMED CONSENT 


\section{INFORMED CONSENT}

1. INFORMED CONSENT FOR “Can the Talk Test Be Used to Control Exercise Intensity?”

2. I, , give my informed consent to participate in this study designed to determine whether the Talk Test can control exercise intensity (by holding the Talk Test condition constant). I have been informed that the study is under the direction of Carl Foster Ph.D. who is a Professor in the Department of Exercise and Sport Science at the University of Wisconsin-La Crosse. I consent to the presentation, publication, and other release of summary data from the study which is not identifiable with myself.

3. I have been informed that my participation in this study will:

a. Require me to perform two maximal exercise treadmill tests, one using a breathing value, and one without.

b. Require me to perform four separate runs of 30 minutes each on a treadmill. Each run will correspond to a different intensity previously determined from the results of my maximal treadmill tests.

c. Require me to have my performance measured quantitatively by measuring my heart rate, rate of perceived exertion, blood lactate, and running speed. I understand that my individual results will contribute to overall group data that may eventually be published. However, any information released will not identify me personally.

4. I have been informed that there are no risks associated with this study other than the fatigue and muscle soreness normally associated with higher intensity 
exercise, and the minor discomfort associated with drawing blood from the fingertip.

5. I have been informed that there are no primary benefits to myself other than the knowledge of my $\mathrm{VO}_{2}$ max, Ventilatory Threshold, and my physiological responses such as heart rate, rate of perceived exertion, blood lactate, and running speed. I understand that while this study poses no direct benefits to me, it does provide free exercise testing that I normally may not have available to me. Based on the results of this study, we may better be able to understand the potential of the Talk Test to control exercise intensity, therefore adding to the existing research.

6. I have been informed that the investigator will answer questions regarding the procedures throughout the course of the study.

7. I have been informed that I am free to decline to participate or to withdraw from the study at any time without penalty.

8. Concerns about any aspects of this study may be referred to Dr. Foster at (608) 785-8687. Questions regarding the protection of human subjects may be directed to the Chair of the UW-L Institutional Review Board at (608) 785-6892.

Investigator:

Participant (print name):

Signature:

Date: 
I have observed the informed consent process for this subject and am writing my name below to signify that I believe that the subject understands the nature of the study and the risks that they are being asked to assume.

Witness: 
APPENDIX C

REVIEW OF LITERATURE 


\section{REVIEW OF LITERATURE}

While it is established that regular exercise provides a variety of health benefits, it is unclear what is appropriate for individual exercise prescription. Based on a substantial body of evidence from experimental training studies, exercise prescription has traditionally been based on relative percentages of maximal exercise test results such as heart rate (HRmax), heart rate reserve (HRR), oxygen uptake $\left(\mathrm{VO}_{2} \mathrm{max}\right)$, percent oxygen uptake $\left(\% \mathrm{VO}_{2} \mathrm{max}\right)$, peak power output (PPO), ventilatory threshold (VT), lactate threshold (LT), respiratory compensation threshold (RCT), and maximal lactate steady state (MLSS) (ACSM, 2010; Mezzani et al. 2012). However, lack of both resources and the availability of trained professionals to conduct maximal exercise tests has dictated that ideal methods of exercise prescription are impractical.

Research conducted by Katch, V., Weltman, A., Sady, S., \& Freedson, P. (1978) concluded that prescribing exercise intensity based on the Relative Percent Concept produces enormous error. More specifically, the data suggested that when subjects were all exercising at the same relative percent heart rate (HR), the onset of metabolic acidosis (represented by each individual's anaerobic threshold) was inconsistent across the subject pool. This is in agreement with research later conducted by Goode, R. C., Mertens, R., Shaiman, S., \& Mertens, J. (1998) stating that maximal heart rate (HRmax) does not correlate well with the anaerobic threshold. Therefore, using the Relative Percent 
Concept to prescribe training heart rates (in terms of \%HRmax) is an inaccurate way of monitoring exercise intensity.

These findings are in agreement with a study later conducted by ScharhagRosenberger, F., Meyer, T., Gassler, N., Faude, O., \& Kindermann, W. (2009) that examined the variability in metabolic responses to exercise at given percentages of $\mathrm{VO}_{2}$ max. Subjects' blood lactate [HLa] concentrations were recorded as a means to measure metabolic responses. Each subject completed a total of four exercise tests: 1) a rampwise incremental cycling test to exhaustion, 2) a stepwise cycling test to exhaustion, 3) a prolonged exercise bout clamped at $60 \%$ of their $\mathrm{VO}_{2} \mathrm{max}$, and 4) a prolonged exercise bout clamped at $75 \%$ of their $\mathrm{VO}_{2}$ max. The findings of this study concluded that when exposed to exercise intensities at the same percentage values of $\mathrm{VO}_{2} \max$, each subjects’ [HLa] varied considerably. More specifically, at higher percentages of $\mathrm{VO}_{2} \max$, there is greater variability in metabolic responses ([HLa]) than at lower percentages of $\mathrm{VO}_{2}$ max. These findings further support the argument that prescribing exercise intensity based on relative percent values is extremely inaccurate. This is especially true if particular training effects are intended because as demonstrated by the earlier study conducted by Katch et al. (1978), objective responses to exercise intensity are often quite different than the corresponding subjective responses.

The American College of Sports Medicine (ACSM, 2010) has published exercise guidelines for both general and clinical populations. Exercise prescription is based on the F.I.T.T. Principle, representing frequency, intensity, time, and type of exercise. While frequency, time, and type of exercise are relatively simple to comprehend, exercise intensity is the most difficult aspect of an exercise training program to correctly 
prescribe. This has been a problem for the general population, for athletes, and in medically prescribed exercise programs. The reason for this is simply that every individual's physiology is different and therefore, objective measures of exercise intensity do not always produce the same subjective results (Katch et al. 1978; ScharhagRosenberger et al. 2009). This, together with the lack of availability of maximal exercise testing results (which are central requirements of the relative percent concept) has led to the popularization of subjective methods of measuring exercise intensity such as the Rating of Perceived Exertion Scale (RPE) (Borg, 1998) and the Talk Test (TT). While the RPE scale has been widely accepted in the field of exercise physiology, particularly into the majority of cardiac rehab programs, (cf. Eston, 2012) the TT has remained somewhat less well accepted.

The concept behind the TT was originally articulated in 1939 by Professor Henry Joseph Grayson through advice he gave to British mountaineers to "climb no faster than you can talk.” This simple recommendation is the groundwork for what may be a superior subjective method of measuring exercise intensity, the Talk Test (TT). The TT has been further studied and developed since it was included in the ACSM Guidelines for Exercise and Training volume 4 in 1991. However, it has since been taken out of the guidelines due to lack of support from other major organizations. More recently, a substantial body of evidence supporting the validity of the TT has emerged, both from our laboratory (Brawner et al. 2006; Cannon et al. 2004; Dehart-Beverly, M., Foster, C., Porcari, J. P., Fater, D. C. W., \& Mikat, R. P. 2000; Foster et al. 2008; Foster et al. 2012; Persinger, R., Foster, C., Gibson, M., Fater, D. C. W., \& Porcari, J.P., 2004; RodriguezMarroya, J. A., Villa, G., Garcia-Lopez, J., \& Foster, C., 2012; Voelker et al. 2001) and 
elsewhere (Loose et al. 2012, Norman, J. F., Kracl, D., Parker, D., \& Richter, A., 2002, Norman, J.F., Hopkins, E., \& Crapo, E. 2008, Zanettini et al. 2012.)

The protocol for the TT is quite simple. The individual performs incremental exercise, with stages of two to three minutes duration. Near the end of each stage, the individual uses a standard speech provoking stimulus, and is asked "can you speak comfortably?” There are three results that can be achieved; a positive TT, which in this study was indicated by both the Last Positive stage (LP) or the stage prior to the Last Positive stage (LP-1), an equivocal (EQ) test, and a negative (NEG) test. In order to attain a positive TT, the subject must be able to speak comfortably while exercising. If the subject is at all unsure whether they are able to speak comfortably, this results in an EQ TT. If the subject is definitely unable to speak comfortably during an exercise test, this results in a NEG TT. Different protocols have been used in studies conducting the TT but the two most common are: 1) having the subject read a standard paragraph during the last thirty 30 seconds of each exercise stage, commonly the Pledge of Allegiance (POA) or 2) having the subject listen to a previously recorded interview and respond to the questions out loud. The subjects are then asked if they are able to speak comfortably, and they can answer in one of three ways; 1) “yes”, indicating a positive test, 2) “I’m not sure”, or anything but a “yes”, indicating an EQ test, and 3)” No”, indicating a NEG test.

Since Grayson introduced the idea of the TT, research has continued to evaluate its validity and reproducibility. In the study mentioned previously by Goode et al. (1998), data revealed that when subjects, (being healthy young males) could "hear their breathing”, they were exercising near their VT. The subjects being able to hear their breathing was assumed to equate to the LP stage of the TT. The HR's associated with 
this intensity were within the recommended guidelines published by the ACSM, therefore suggesting the concept of the TT to be a valid method of correctly measuring exercise intensity. These results were in agreement with a previous study by Czaplicki, T. E., Keteyian, S. J., Brawner, C. A., \& Weingarten, M. A. (1997).

The logic behind the TT is related to the principles of speech production. Meckel, Y., Rotstien, A., \& Inbar, O. (2002) examined the cardiopulmonary and metabolic responses to speech during exercise of varying intensities in healthy young men. They found that to allow adequate speech production, one must adapt their breathing pattern to one that allows them to take in the required amount of oxygen. The results of this study concluded that speech production is correlated with an increase in oxygen cost, a decrease in oxygen consumption, and therefore a decrease in ventilatory efficiency. During speech production, inspiration time decreases while expiration time increases resulting in a significant decrease in overall ventilation. More specifically, the decrease in $\mathrm{VO}_{2}$ during speech while exercising was accompanied by a significant drop in ventilation as well as an increase in [HLa] concentration. However, only the lowest intensity exercise bout produced such changes in [HLa] and it remains unclear as to why the increases in the other two (more difficult) exercise bouts were smaller and not significant.

With this information considered, an observation that breathing frequency increases markedly at the intensity of the VT, it is common sense that during exercise at higher intensities, speech production becomes more difficult. This concept is what has led researchers to believe that the TT is highly related to VT. Dehart-Beverly et al. (2000) produced results indicating that the TT is a surrogate of the VT. Results from this 
study suggested that during the positive stages of the TT, subjects were exercising below their VT (and within recommended guidelines from the ACSM). During the NEG stage of the TT, subjects were exercising beyond their VT (therefore exceeding the ACSM recommendations for exercise). The EQ stage occurred at exercise intensities essentially equal to the VT. These findings were reproduced in several other studies with different subject populations conducted by, Voelker et al. (2000); Recalde et al. (2000); Persinger et al. (2004); \& Foster et al. (2008, 2012).

With evidence supporting the validity of the TT in healthy populations, research was lacking in regards to applying the TT to clinical populations. In 2002, Voelker and colleagues evaluated the relationship between the TT and VT in patients with stable cardiovascular disease. Subjects performed two maximal treadmill tests, one with gas analysis to establish each subjects $\mathrm{VO}_{2}$ and VT, and a second measuring TT responses. While reciting the POA, each subject answered yes (positive test), not sure (EQ test ), or no (NEG test) to the question, “Can you speak comfortably?”. The results were consistent across the subject pool suggesting that at the (LP) and equivocal (EQ) stages of the TT, subjects were at or below their VT and when subjects were at the negative (NEG) stage of the TT, they were above their VT (Voelker et al. 2002).

In 2006, Brawner and colleagues evaluated the ability of the TT to guide exercise intensity in patients with coronary artery disease (CAD). The findings of this study were in agreement with Goode’s (1998) study, suggesting that on average, using the TT resulted in HR's and RPE's within the recommended guidelines from the ACSM. More importantly, HR's were also similar to the HR's at each subjects' VT. What made this study even more relevant is that it used both speech provoking stimuli, the POA being 
read at the end of each exercise stage, and each subject responding (out loud) to recorded interview questions while exercising on an indoor track. There was a correlation of 0.71 between the two stimuli suggesting the TT to be a valid method of measuring exercise intensity despite the type of speech provoking stimuli (Brawner et al. 2006).

With research confirming that the TT can be applied to patients with CAD, the question remained if the TT could be used to prescribe exercise intensity in patients with exertional ischemia. Due to the fact that people with exertional ischemia are at an increased risk of having cardiac events during exercise, it is essential that exercise prescription be accurate in this population. Cannon et al. (2004) evaluated whether the TT could be used to correctly prescribe exercise in patients with exertional ischemia. The results of this study showed that the exercise time, HR, and rate pressure product (RPP) were significantly lower at the LP stage of the TT than at the first onset of electrocardiographic evidence of ischemia. More specifically, in $84 \%$ of the subjects, the LP stage of the TT preceded the ischemic threshold and produced HR's approximately 10 beats below the onset of ischemic symptoms. These HR's were also within the ACSM's recommendations for target heart rate in patients with exertional ischemia. This suggests that the TT can and should be applied to people with exertional ischemia. However, the small number of subjects in this study warrants further research to be done on this topic.

With the TT being deemed valid for measuring exercise intensity is healthy and clinical populations, it was unknown if the TT could be applied to athletic or well-trained individuals. Recalde et al. (2002) investigated if the TT served as a valid surrogate of the VT in well-trained adults. His results were consistent with the similar studies on the TT in healthy and clinical populations in that when subjects could speak comfortably, they 
were below their VT and when subjects could not speak comfortably, they were exercising at an intensity at or beyond their RCT.

At this point, the TT was considered to be a valid method of measuring exercise intensity. However, research was lacking in terms of whether it can be translated to exercise prescription. Persinger et al. (2004) evaluated the consistency of the TT for exercise prescription by measuring the relationship between the TT and the VT on the treadmill and cycle ergometer. In both modes of exercise, the $\mathrm{VO}_{2}$ at VT at the positive, EQ, and NEG stages of the TT were well correlated. The data therefore supported their hypothesis that the validity of the TT to measure exercise intensity was consistent across different modes of exercise.

In a similar study conducted by Foster et al. (2008), four independent series of experiments were conducted. Each series experimentally manipulated either the VT or the exercise protocol and then measured TT responses in relation to the VT. All subjects performed two maximal exercise tests on a motorized treadmill. In series one, subjects completed one of the two tests before and after donating $500 \mathrm{ml}$ of whole blood (designed to decrease the VT). In series two, subjects completed two tests before and after completing a six week aerobic training program (designed to increase VT). In series three, subjects performed two interval exercise training sessions on a cycle ergometer. TT responses were recorded in response to the intensity (e.g. above and below their VT). In series four, subjects completed two exercise training sessions on the treadmill while the VT was manipulated to be above and below their VT in random order. Remarkably, in all four series of experiments, the data revealed the VT and the TT to be "robustly related.” The significance of this particular study is that unlike the previous studies, the 
researchers manipulated the VT and the exercise protocol in several ways, rather than only observing correlated responses. This further supports the idea that the TT is a valid surrogate of the VT and more importantly, can correctly be applied to exercise prescription.

In 2009, Foster and colleagues conducted a separate study evaluating the translation of submaximal exercise test responses to exercise prescription in sedentary adults. More specifically, this study examined what happens to exercise intensity when TT responses are applied to steady state exercise training. This randomized observational study required subjects to perform an incremental treadmill test where HR, RPE, and TT responses were recorded. This was done to measure at what intensities each subject was working during each stage of the TT. Subjects then performed three 20-minute exercise bouts with the workload (during the last 10 minutes of each bout) adjusted to be at the absolute intensity of: 1) the LP-1 stage, 2) the LP stage, and 3) the EQ stage. In all three stages, the steady state exercise produced objective results of \%HRmax and MET levels within ACSM's guidelines. However, the subjective responses of the subjects exceeded the ACSM guidelines. More specifically, without decreasing the absolute intensity by one level before comfortable speech was last observed, subjects could not produce adequate speech. This study further reinforces the inaccuracy of prescribing exercise based on solely objective results (Foster, C., Porcari, J. P., Gibson, M., Greany, J., Talati, N., \& Recalde, P., 2009).

The concept that exercise intensity needed to be reduced to that of the stage before the LP stage lead to the research conducted by Jeans, E. A., Foster, C., Porcari, J. P., Gibson, M, \& Doberstein, S. (2011) that evaluated how much of a reduction in 
absolute exercise intensity was needed to produce adequate speech in well-trained individuals. Similar to Foster's work in 2009, her results showed that for well-trained or athletic populations, absolute exercise intensity should be reduced to that of the LP-1 and LP stages. This data suggested that the TT was not only strong in its validity, but its reproducibility as well.

In 2012, Foster and colleagues evaluated the ability of TT responses during an exercise test to guide exercise training in competitive runners. Steady state conditions were observed at the absolute intensity associated with the LP stage of the TT. However, absolute intensities at the EQ stage of the TT produced results (HR, [HLa], RPE, and speech comfort) that exceeded steady state conditions. These results are in agreement with the study by Jeans et al. 2011 but differ from the results of the study conducted by Foster et al. 2009 in that steady state conditions were observed at the LP stage instead of the LP-1 stage (Foster et al. 2012).

In addition to the TT being highly related to the VT, research has shown it to be highly related to the LT as well. Quinn \& Coons (2011) conducted a study that aimed to identify differences between measured physiological and perceptual variables at the LT and VT. In addition they examined what effects the TT had on such variables at each threshold and if they were comparable. The results demonstrated that during the positive stage of the TT, subjects were below their LT. During the EQ and NEG stages of the TT, subjects were above their LT. Additional findings of this study were that: 1) the physiological and perceptual values during the LP stage of the TT were significantly lower than physiological and perceptual values recorded at the LT and, 2) the physiological and perceptual values during the EQ and NEG TT stages were significantly 
higher than physiological and perceptual values at the LT. These findings suggest that in response to the TT, VT and LT produce comparable effects during the positive, EQ, and NEG stages, supporting the concept that the TT is a valid surrogate method of both physiological markers.

The only study conducted thus far evaluating the ability of subjective measurements of exercise clamped at a constant intensity to control exercise intensity was a study by Parfitt, G., Evans, H. \& Eston, R. (2012). This study measured the ability of a Perceptually Regulated Training (PRET) clamped at an RPE of 13 to improve aerobic fitness and cardiovascular health. Due to the variability of subjective responses to exercise intensity previously examined in other studies (Katch et al. 1978; ScharhagRosenberger et al. 2009), clarification of how to accurately prescribe exercise remains problematic. In this randomized study, sedentary volunteers were assigned to a training group or a control group. All subjects completed a maximal incremental exercise test to measure their aerobic capacity. The training group then followed a PRET program clamped at an RPE of 13 three times a week for eight weeks while the control group participated in no training at all. The data revealed that in the training group, both fitness and cardiovascular health improved. Specifically, a PRET program clamped at an RPE of 13 produced improvements in $\mathrm{VO}_{2}$ max, mean arterial pressure (MAP), total cholesterol, and body mass index (BMI). Additionally, the training program clamped at an RPE of 13 produced intensities that the subjects reported to feel "pleasant.” In contrast, the control group had a decline in their fitness and overall health.

This study is of particular significance to our study because it suggests that clamping the exercise intensity at an RPE of 13 produces: 1) physiological responses 
within ACSM’s Guidelines and 2) improvements in overall fitness and cardiovascular health. An RPE of 13 is approximately the same as the intensity perceived at the LP stage of the TT. Therefore, clamping exercise intensity to that of the intensity of the LP stage should produce physiological responses within ACSM's Guidelines and lead to improvement in overall fitness and cardiovascular health.

By completing our proposed study, we hope to find whether clamping the exercise intensity to that of each subjects' positive stage can produce improvements in overall fitness and cardiovascular health. In addition, we will evaluate what effects occur when exercise intensity is clamped at those associated with each subjects' EQ and NEG stages of their TT. 


\section{REFERENCES}

American College of Sports Medicine, (2010). ACSM's Guidelines for Exercise Testing and Prescription $8^{\text {th }}$ edition. Maryland: Lippincott Williams \& Wilkins for the American College of Sports Medicine.

Borg, G. Borg's Perceived Exertion and Pain Scales. Champaign, IL: Human Kinetics; 1998.

Brawner, C. A., Vanzant, M. A., Ehrman, J. K., Foster, C., Porcari, J. P., Kelso, A. J., \& Keteyian, S. J. (2006). Guiding exercise using the talk test among patients with coronary artery disease. Journal of Cardiopulmonary Rehabilitation, 26, 72-75.

Cannon, C., Foster, C., Porcari, J. P., Skemp-Arlt, K. M., Fater, D. C. W., \& Backes, R. (2004). The talk test as a measure of exertional ischemia. American Journal of Medicine and Sports, 6, 52.

Czaplicki, T. E., Keteyian, S. J., Brawner, C. A., \& Weingarten, M. A. (1997). Guiding exercise training intensity on a treadmill and dual-action bike using the talk test. Medicine and Science in Sports and Exercise, 29, 70 (abstract).

Dehart-Beverly, M., Foster, C., Porcari, J. P., Fater, D. C. W., \& Mikat, R. P. (2000). Relationship between the talk test and ventilatory threshold. Clinical Exercise Physiology, 2, 34-38.

Eston, R. (2012). Use of ratings of perceived exertion in sports. International Journal of Sports Physiology and Performance, 7, 175-182.

Foster, C., Porcari, J. P., Anderson, J., Paulson, M., Smaczny, D., Webber, H., \& Doberstein, S. T. (2008). The talk test as a marker of exercise training intensity. Journal of Cardiopulmonary Rehabilitation and Prevention, 28, 24-30

Foster, C., Porcari, J. P., Gibson, M., Wright, G., Greany, J., Talati, N., \& Recalde, P. (2009). Translation of submaximal exercise test responses to exercise prescription using the talk test. Journal of Strength and Conditioning Research, 23(9), 2425-2429

Foster, C., Porcari, J. P., de Koning, J. J., Bannwarth, E., Condello, G., Galamback, K., Gibson, M, Lueck, J., Rodriguez-Marroyo, J. A., \& Walraven, L. (2012). Exercise training for performance and health. Dtsch Z Sportmed, 63, 69-74. 
Goode, R. C., Mertens, R., Shaiman, S., \& Mertens, J. (1998). Voice, breathing, and the control of exercise intensity. Advances in Experimented Medicine and Biology, 450, 223-229.

Jeans, E. A., Foster, C., Porcari, J. P., Gibson, M, and Doberstein, S. (2011). Translation of exercise testing to exercise prescription using the talk test. Journal of Strength and Conditioning Research, 25(3), 590-596.

Katch, V., Weltman, A., Sady, S., \& Freedson, P. (1978). The validity of the relative percent concept for equating training intensity. European Journal of Applied Physiology and Occupational Physiology, 39(4), 219-227.

Loose, B. D., Christensen, A. M., Smolcyzyk, J. E., Roberts, K. L., Budziszewska, A., Hollatz, C. G., \& Norman, J. F. (2012). Consistency of the counting talk test for exercise prescription. Journal of Strength and Conditioning, 26(6), 1701-1707.

Meckel, Y., Rotstien, A., \& Inbar, O. (2002). The effects of speech production on physiologic responses during submaximal exercise. Medicine \& Science in Sports \& Science, 34(8), 1337-1343.

Mezzani, A., Hamm, L. F., Jones, A. M., McBride, P. E., Moholdt, T., Stone, J. A., Urhausen, J. P., \& Williams, M. A. (2012). Aerobic exercise intensity assessment and prescription in cardiac rehabilitation. Journal of Cardiopulmonary Rehabilitation and Prevention, 32, 327-350.

Norman, J. F., Kracl, D., Parker, D., \& Richter, A. (2002). Comparison of the counting talk test and heart rate reserve methods for estimating exercise intensity in healthy young adults. Journal of Exercise Physiology Online, 5, 15-22.

Norman, J. F., Hopkins, E., \& Crapo, E. (2008). Validity of the counting talk test in comparison with standard methods of estimating exercise intensity in young healthy adults. Journal of Cardiopulmonary Rehabilitation and Prevention, 28, 199-202.

Parfitt, G., Evans, H., \& Eston, R. (2012). Perceptually regulated training at RPE13 is pleasant and improves physical health. Medicine \& Science In Sports \& Exercise, 44(8), 1613-1618.

Persinger, R., Foster, C., Gibson, M., Fater, D. C. W. \& Porcari, J. P. (2004). Consistency of the talk test for exercise prescription. Medicine \& Science in Sports \& Exercise, 36(9) 1632-1636.

Quinn, T. J., \& Coons, B. A. (2011). The talk test and its relationship with the ventilatory and lactate thresholds. Journal of Sports Sciences, 29(11), 1175-1182 
Recalde, P. T., Foster, C., Skemp-Arlt, K. M., Fater, D. C. W., Neese, C. A., Dodge, C., \& Porcari, J. P. (2002). The 'talk test' as a simple marker of ventilatory threshold. South Africa Sports Medicine, (9) 5-8.

Rodriguez-Marroyo, J. A., Villa, G., Garcia-Lopez, J., \& Foster, C. (2012). Relationship between the talk test and ventilatory threshold in well-trained cyclists.

doi:10.1519/JSC.0b013e3182736af3

Scharhag-Rosenberger, F, Meyer, T., Gassler, N, Faude, O., \& Kindermann, W. (2009). Exercise at given percentages of VO2max: Heterogeneous metabolic responses between individuals. Journal of Science and Medicine in Sport, 13, 74-79.

Voelker, S. A., Foster, C., Porcari, J. P., Skemp, K. M., Brice, G., \& Backes, R. (2002). Relationship between the talk test and ventilatory threshold in cardiac patients. Clinical Exercise Physiology, 4(2), 120-123.

Zanettini, R., Centeleghe, P., Franzelli, C., Mori, I., Benna, S., Penati, C. and Sorlini, N. (2012). Validity of the talk test for exercise prescription after myocardial revascularization. European Journal of Preventative Cardiology, 20(2), 376-382. 